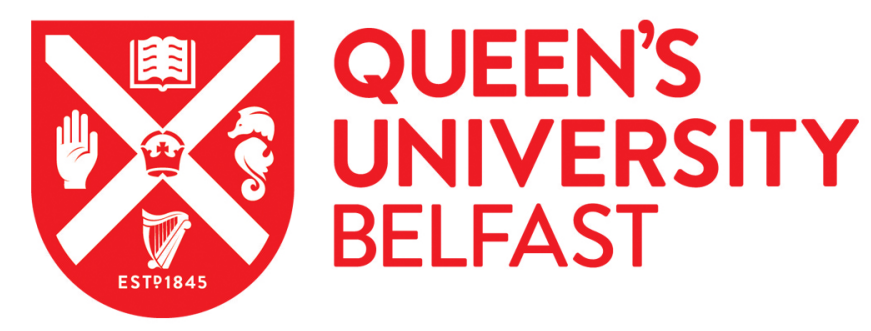

\title{
Physicochemical characterization and kinetic modelling concerning combustion of waste berry pomace
}

Osman , A. I., Young, T. J., Farrell, C., Harrison, J., Al-Muhtaseb, A. H., \& Rooney, D. W. (2020).

Physicochemical characterization and kinetic modelling concerning combustion of waste berry pomace. ACS

Sustainable Chemistry \& Engineering, 8(47), 17573-17586. https://doi.org/10.1021/acssuschemeng.0c07390

Published in:

ACS Sustainable Chemistry \& Engineering

Document Version:

Peer reviewed version

Queen's University Belfast - Research Portal:

Link to publication record in Queen's University Belfast Research Portal

Publisher rights

Copyright 2020 ACS. This work is made available online in accordance with the publisher's policies. Please refer to any applicable terms of use of the publisher.

\section{General rights}

Copyright for the publications made accessible via the Queen's University Belfast Research Portal is retained by the author(s) and / or other copyright owners and it is a condition of accessing these publications that users recognise and abide by the legal requirements associated with these rights.

Take down policy

The Research Portal is Queen's institutional repository that provides access to Queen's research output. Every effort has been made to ensure that content in the Research Portal does not infringe any person's rights, or applicable UK laws. If you discover content in the Research Portal that you believe breaches copyright or violates any law, please contact openaccess@qub.ac.uk. 


\title{
combustion of waste berry pomace
}

\section{Physicochemical characterization and kinetic modelling concerning}

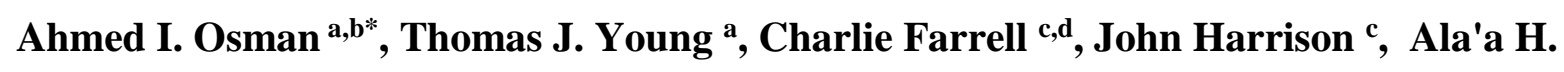

Al-Muhtaseb ${ }^{\text {e, David W. Rooney }}{ }^{\text {a }}$

a School of Chemistry and Chemical Engineering, Queen's University Belfast, Belfast BT9 5AG, Northern Ireland, UK

${ }^{\mathrm{b}}$ Chemistry Department, Faculty of Science, South Valley University, Qena 83523 - Egypt.

${ }^{c}$ South West College, Cookstown, Co. Tyrone, BT80 8DN, Northern Ireland, UK.

${ }^{\mathrm{d}}$ School of Mechanical and Aerospace Engineering, Queen's University Belfast, Belfast BT9 $5 \mathrm{AH}$, Northern Ireland, UK.

${ }^{\mathrm{e}}$ Department of Petroleum and Chemical Engineering, College of Engineering, Sultan Qaboos University, Muscat, Oman.

Email: $\underline{\text { aosmanahmed01@qub.ac.uk, }}$

Address: School of Chemistry and Chemical Engineering, Queen's University Belfast, David Keir Building, Stranmillis Road, Belfast BT9 5AG, Northern Ireland, United Kingdom

\author{
Fax: +442890974687
}

Tel.: +442890974412 


\section{Abstract}

2 Herein waste biomass (blackberry pomace) was physicochemically characterized and its

3 thermochemical products. This is coupled with the evaluation of the kinetic triplet (activation

4 energy, pre-exponential constant and the rate of reaction) and thermal predictions for the

5 combustion process for the first time via the AKTS thermokinetics package. The main kinetic

6 modelling method employed was the differential iso-conversional analysis; however, the

7 Flynn-Wall-Ozawa and ASTM E-698 methods were used as a comparison. The model was

8 developed and validated from experimental DSC and TGA data; resulting in an excellent match

$9 \quad\left(R^{2}=0.99544\right.$ and 0.99194 , respectively). The activation energies were evaluated using the 10 ASTM-E698 method (88.64 kJ.mol $\left.{ }^{-1}\right)$ and Ozawa-Flynn-Wall methods $\left(50-140 \mathrm{~kJ}^{\mathrm{mol}}{ }^{-1}\right)$. The differential iso-conversional method showed activation energy values were in the range of 84$197 \mathrm{~kJ} \cdot \mathrm{mol}^{-1}$ for the combustion of berry pomace. Isothermal predictions based on the model indicated at temperatures of $560{ }^{\circ} \mathrm{C}$ and $600^{\circ} \mathrm{C}$; the reaction had achieved $100 \%$ completion $(\alpha=1)$ after 30 and 6 minutes, respectively. For the non-isothermal prediction, the heating rates of 50,75 and $100{ }^{\circ} \mathrm{C} / \mathrm{min}$ have a two-stage rate profile with a maximum peak in the first stage of the reaction. Thereafter, the reaction rate increases once again but not to the same effect as the first initial stage. For instance, at $100{ }^{\circ} \mathrm{C} / \mathrm{min}$, stage 1 and 2 are reported as 0.005381 and $0.005148 \mathrm{~s}^{-1}$, respectively. Overall, this study demonstrates the success of the approach in modelling the thermochemical conversion of berry pomace as waste stream biomass.

Keywords: Combustion, Thermal analysis, Kinetic modelling, Biomass, Pomace, Isoconversional. 


\section{Introduction}

2

3 The global demand for food, energy and medicinal products is constantly increasing to meet

4 the demands of society ${ }^{1}$ and has led to a decline in hydrocarbon reserves and environmental

5 damage ${ }^{2}$. The requirement of energy is expected to grow by approximately $50 \%$ over the next

620 years, with projections reaching 778 EJ by 2035. Extracting energy from biomass waste

7 streams has gained increased attention from academia and industry and has resulted in

8 directives such as the EU2020, whereby renewable energy increases to $20 \%$ by 2020 with a

9 commensurate reduction in greenhouse gas emissions and increase in overall energy efficiency

$10{ }^{3}$. Biomass streams include wood, grasses or agricultural residues which are readily available

3b. One such residue is blackcurrant pomace which is a mixture of the skins, pulp, seeds and stems of the berries ${ }^{4}$. While the juice is the primary product, the extraction of anthocyanin and antioxidants from berry pomace can result in additional revenue streams, after which it is commonly sent to composting instead of being utilised for energy or char production. These anthocyanin and antioxidant products are often used for eyesight therapies while other researchers have focussed on the use of berry pomace for increased fibre and phenol content within foods such as bread and other cereal products ${ }^{5}$.

In addition to energy conversion, there also exists the opportunity to develop biochar which is a useful adsorbent material for heavy metal extraction from contaminated water mass ${ }^{6}$. It has been reported previously, that the biomass material once pyrolysed has improved structural and surface properties which promote such applications ${ }^{3 b}$.

At present, there are 12 varieties of blackcurrant grown within the UK with an estimated value or $£ 10$ million per annum ${ }^{7}$. Countries with the most suitable growing conditions include Russia, Ukraine, Poland and Hungary. In 2016, Russia and Poland accounted for 60.3 and 25.4\%, respectively of the 655,000 metric tonnes produced ${ }^{8}$. Despite these volumes, very little 
1 research is currently available as modeling of the behaviour of this material during

2 thermochemical conversion. Thermochemical conversion processes include combustion,

3 pyrolysis, gasification and liquefaction ${ }^{3 \mathrm{~b}}$ and can result in vapour/gas, liquid, and solid product

4 streams. Solid fractions such as ash can have a high composition of Nitrogen-Phosphorous-

5 Potassium (N-P-K), and so may have the potential to be used in the agricultural sector 9 .

6 Thermal and kinetic analysis is useful when considering the design of biomass 7 combustion/pyrolysis systems as biomass is composed of three main constituent parts: 8 cellulose, hemicellulose and lignocellulose. Therefore it is inaccurate to state that the biomass 9 possesses only one $E_{a}$, each constituent has three individual values representing the reaction pathway, and therefore, the process requires nine separate $E_{a}$ values. For simplification, either a single value or a range is generally reported for a specific feedstock. To obtain the data, model-free methods such as Kissinger, Flynn-Wall-Ozawa (FWO) and Kissinger-AkahiraSunose (KAS) are often used. It is possible to determine the activation energy $\left(\mathrm{E}_{\mathrm{a}}\right)$ as a function of the extent of conversion with no pre-requisite requirement of the decomposition reaction mechanism. This can be obtained through a varied range of thermal gravimetric analysis (TGA) and differential scanning calorimetry (DSC). Osman et al. reported that the activation energies for miscanthus varied from $40-165 \mathrm{~kJ} \mathrm{~mol}^{-1}$ via the differential iso-conversional method throughout the progress of the reaction ${ }^{3 b}$.

From literature, there is limited knowledge available on the $\mathrm{E}_{\mathrm{a}}$ of blackberry pomace to perform kinetic modelling. The only values available for the $\mathrm{E}_{\mathrm{a}}$ focus on blackberry seed oil. It was reported by Micić et al. that the $E_{a}$ for blackberry seed oil was $101 \pm 4$ and $90 \pm 10 \mathrm{~kJ} \cdot \mathrm{mol}^{-1}$ for the onset temperature $\left(\mathrm{T}_{\mathrm{on}}\right)$ and the first peak $\left(\mathrm{T}_{\mathrm{P} 1}\right)$, respectively. $\mathrm{T}_{\mathrm{on}}$ and $\mathrm{T}_{\mathrm{P} 1}$ correspond to the DSC curve for the blackberry seed oil ${ }^{10}$. Kayran et al. studied the energy content within apricot pomace, the $\mathrm{E}_{\mathrm{a}}$ for this biomass crop waste material was found to be $19.41 \mathrm{~kJ}^{\mathrm{mol}}{ }^{-1}$. This is comparative to carrot pomace, apple pomace, industrial grape pomace and apricot kernels, were 
$1 \quad 23.05,24.51,19.27$ and $16.5 \mathrm{~kJ} \mathrm{~mol}^{-1}$, respectively ${ }^{11}$. In addition, further studies have been

2 conducted on the thermal decomposition of olive pomace under torrefaction operating conditions and the iso-conversional kinetic analysis of such material. From the work conducted by Brachi et al., the $\mathrm{E}_{\mathrm{a}}$ of olive pomace varies from $167.94-994.09 \mathrm{~kJ} \cdot \mathrm{mol}^{-1}$ (linear) and 162.59 - $1069.74 \mathrm{~kJ} \cdot \mathrm{mol}^{-1}$ (non-linear), with the trend set based on the degree of conversion from 0.05 to $0.95^{12}$. According to the authors' knowledge, no pre-existing detailed work that has been performed on the kinetic modelling of blackberry pomace by thermal processes, or its use for energy production.

\section{Materials and methods}

The blackberry pomace used in this study was obtained from a 2018 harvest in Southern Hemisphere (New Zealand) and had been passed through a solvent and press extraction process to remove the anthocyanins and antioxidants. The sample obtained was dried in an oven prior to use.

\section{Pomace Biomass Characterisation}

The samples were characterized using powder X-ray diffraction (XRD), Fourier Transform Infrared (FT-IR) spectroscopy, XPS, Raman, SBET, CHNS and SEM-EDX techniques where their details in the supplementary information. Proximate analysis was carried out according to the ASTM method to determine the \% of moisture (ASTM D2867-95), volatile matter (ASTM D5832-95), ash content (ASTM D2866-94), char and fixed carbon (by difference) ${ }^{13}$. Bomb calorimetry was conducted using a Parr 6200 oxygen bomb calorimeter. Char and volatile contents were determined using Thermogravimetry (TGA), with heating to $900{ }^{\circ} \mathrm{C}$ at a rate of $10{ }^{\circ} \mathrm{C} \cdot \mathrm{min}^{-1}$ and holding the temperature for $10 \mathrm{~min}$ to ensure constant final weight ${ }^{14}$. Again with the TGA, \% Ash was obtained by heating to $500{ }^{\circ} \mathrm{C}$ with a heating rate of $10{ }^{\circ} \mathrm{C} \cdot \mathrm{min}^{-1}$ then heating to $575{ }^{\circ} \mathrm{C}$ with $2.5^{\circ} \mathrm{C} \cdot \mathrm{min}^{-1}$ and holding for $10 \mathrm{~min}{ }^{14}$. Scanning Electron TGA 
1 was performed from $25-600^{\circ} \mathrm{C}$ with different heating rates of $2,4,6$ and $8{ }^{\circ} \mathrm{C} \mathrm{min}^{-1}$, in a stream

2 of dry air flowing at $40 \mathrm{~cm}^{3} \cdot \mathrm{min}^{-1}$, using a Mettler Toledo Thermogravimetric analyser Pyris

3 TGA/DSC1. The TGA instrument was also calibrated for buoyancy effects to allow

4 quantitative estimation of weight changes. Experiments were performed twice to ensure

5 reproducibility, and the standard error was found to be $\pm 1{ }^{\circ} \mathrm{C}$. The ICTAC Kinetics Committee

6 has published several documents relating to the problems and correct procedure in the

7 collection of thermoanalytical data and correct performance of kinetic computations of thermal

8 analysis data to provide accurate kinetic modelling ${ }^{15}$. Changes in mass of the sample were

9 recorded during the ramping operation. DSC was used to determine the heat liberated in $\mathrm{W} \cdot \mathrm{g}^{-}$

101 . For the kinetic modeling, the weights of the samples were between 7.22 and $7.74 \mathrm{mg}$ to

11 reduce the effect of heat and mass transfer on the data obtained from the DSC machine. Kinetic modeling was performed using AKTS (Advanced Kinetics and Technology Solutions) software.

\section{Results and Discussion}

Characterisation results

Figure 1 shows the XRD and FTIR results of both raw pomace and the resulting biochar. The XRD diffractogram of both pomace samples (Figure 1 (a)) displays two different phases relating to amorphous and crystalline cellulose with the latter appearing at $2 \theta=22^{\circ}$, corresponding to the crystallographic plane (002) (JCPDS data 03-0289) while the amorphous cellulose at $2 \theta=18^{\circ}$. The crystallinity index (\% CRI) was calculated according to equation 1 .

$$
\% C R I=\frac{\left(I_{002}-I_{a m}\right)}{I_{002}} \times 100
$$

Where: $I_{a m}:$ is the low-intensity peak of the amorphous region at $2 \theta=18^{\circ}$ 
1 The \% CRI was $37.5 \%$ which confirms the presence of the larger fraction of amorphous

2 cellulose, which is low compared to grasses such as miscanthus where Osman et al. reported

3 CRI to be $77.1 \%$ and Hassan et al. reported it as $74 \%{ }^{16}$. However, this result is in line with

4 other work done on fruit pomace, which showed $33.7 \%$ CRI ${ }^{17}$. Even with the pomace biochar,

$5 \%$ CRI decreased to $35.8 \%$ compared to the pomace biomass, as shown in Figure 1. The FTIR

6 spectra of the pomace and its biochar are shown in Figure 1 (b). Here the pomace showed

7 absorption bands at approximately 3433, 2933, 2860, 1740, 1649, 1455 and $1142 \mathrm{~cm}^{-}$

8 , which correspond to $\mathrm{O}-\mathrm{H}$ stretching, $\mathrm{C}-\mathrm{H}$ symmetrical and asymmetric vibration mode of

9 methyl and methylene groups stretching, $\mathrm{CH}_{2}$ stretching vibration, $\mathrm{C}=\mathrm{O}$ (conjugated),

$10 \mathrm{C}=\mathrm{O}$ (non-conjugated or $\mathrm{O}-\mathrm{H}$ ), $\mathrm{C}=\mathrm{O}$ bending and $\mathrm{C}-\mathrm{O}-\mathrm{C}$ stretching, respectively ${ }^{18}$. The

11 absorption bands mentioned above are indicative of the cellulose fingerprint region. The band at 2945 and small band at $3000 \mathrm{~cm}^{-1}$ are both indicative of cellulose as well as the band at 1455 $\mathrm{cm}^{-1}$ due to the C-H stretching. The ester stretching band of C-O-C $\left(1142 \mathrm{~cm}^{-1}\right)$ further supports the presence of cellulose within the pomace structure. On the other hand, calcining the pomace led to the destruction of functional groups within the structure as shown in the biochar FTIR spectra. The absorption band at $1599 \mathrm{~cm}^{-1}$ is attributed to the $\mathrm{C}=\mathrm{C}$ symmetrical stretching in

17 the carbonaceous composition of the char ${ }^{19}$. 

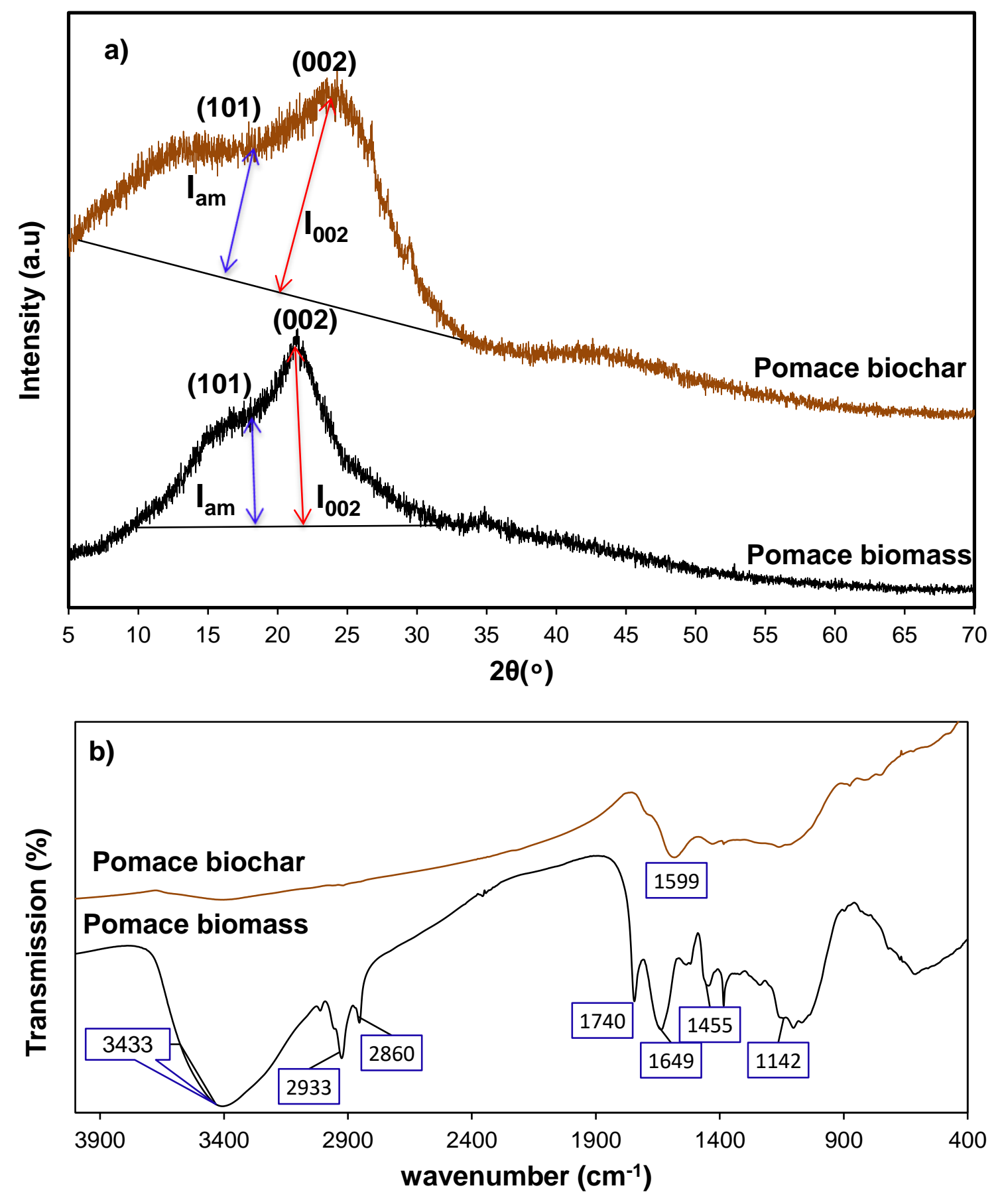

3 Figure 1: XRD patterns of pomace biomass and biochar (a) along with the FTIR results of 4 both samples (b).

5 Figure 2 (a-c) shows the SEM images of the pomace biomass, demonstrating a bulky material

6 with a non-porous structure. This is in line the calculated surface area and pore volume of 0.42

$7 \mathrm{~m}^{2} \cdot \mathrm{g}^{-1}$ and $0.000005 \mathrm{~cm}^{3} \cdot \mathrm{g}^{-1}$, respectively, as seen in Table 1. On the other hand, pomace

8 biochar (Figure $2(\mathrm{~d}-\mathrm{e})$ ) showed a porous structure with a calculated surface area and pore 
1 volume of $44.7 \mathrm{~m}^{2} \cdot \mathrm{g}^{-1}$ and $0.019 \mathrm{~cm}^{3} \cdot \mathrm{g}^{-1}$, respectively. It is worth noting that the pomace ash

2 showed a surface area and pore volume of $6.9 \mathrm{~m}^{2} \cdot \mathrm{g}^{-1}$ and $0.008 \mathrm{~cm}^{3} \cdot \mathrm{g}^{-1}$, respectively. The SEM

3 images of the pomace ash are shown in Figure S1 (supplementary information) using BSED

4 where heavier elements appear brighter. The EDX data of pomace, biochar and ash are shown

5 in Figure S2 (a-c), where the surface structure of the pomace biomass showed only carbon and

6 oxygen with 71.6 and 28.4 wt.\%, respectively. While the pomace biochar showed minor

7 contribution of inorganic elements such as $\mathrm{K}, \mathrm{P}, \mathrm{Mg}$ with wt.\% composition of 2.3, 1.1 and 0.2

8 wt.\%, respectively. As expected, inorganic elements are significantly increased in the pomace

9 ash with values of $28.5,17.3,2.5$ wt.\%, respectively along with other elements such as $\mathrm{Ca}, \mathrm{Na}$

10 and S with wt.\% of 8.0, 1.5 and 1.2 wt.\%, respectively ${ }^{16 \mathrm{~b}, 20}$. Furthermore, the results showed

11 that the pomace ash left after combustion could be used in the fertiliser industry due to the high

$12 \mathrm{~K}$ and $\mathrm{P}$ in its compositions as the typical fertiliser is N-K-P. 


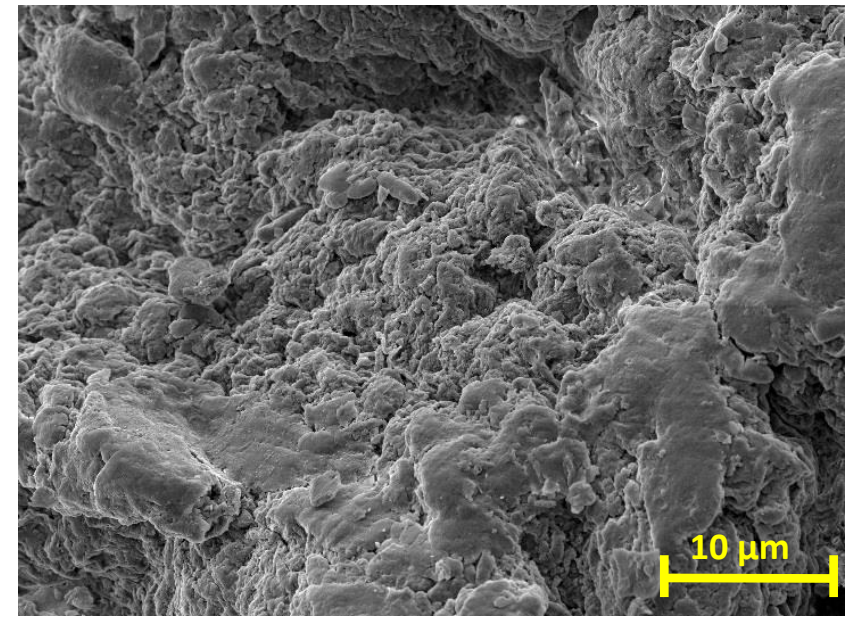

a)

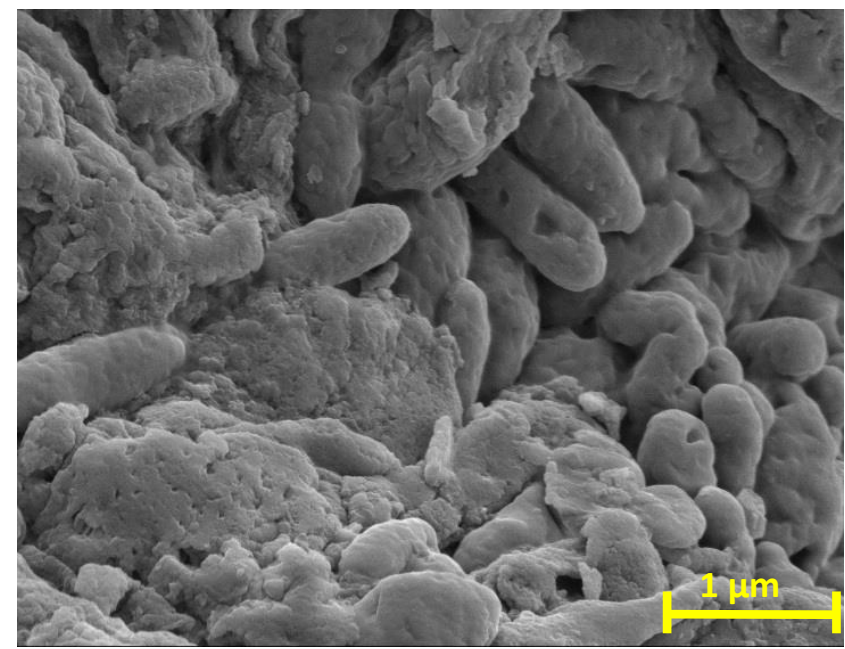

b)

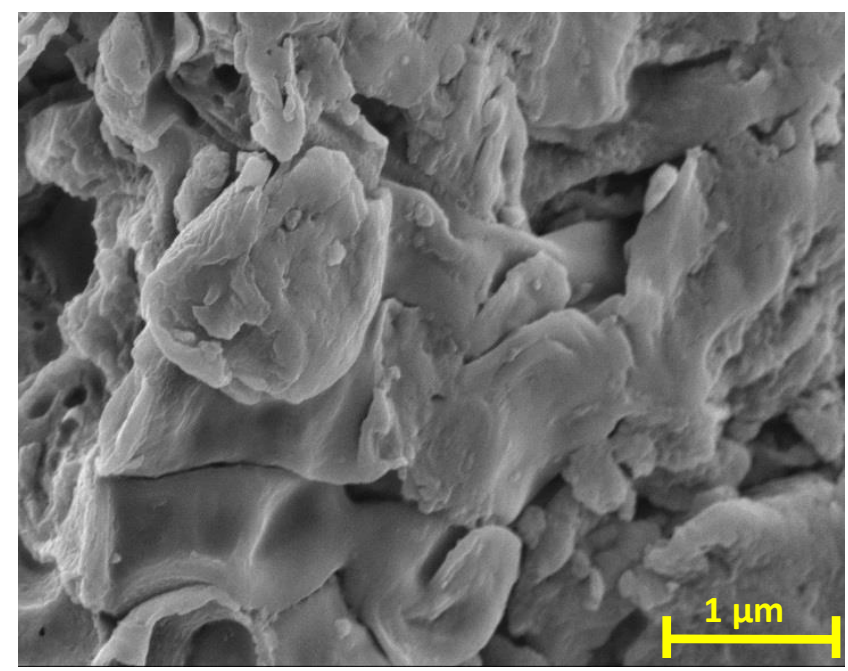

c)

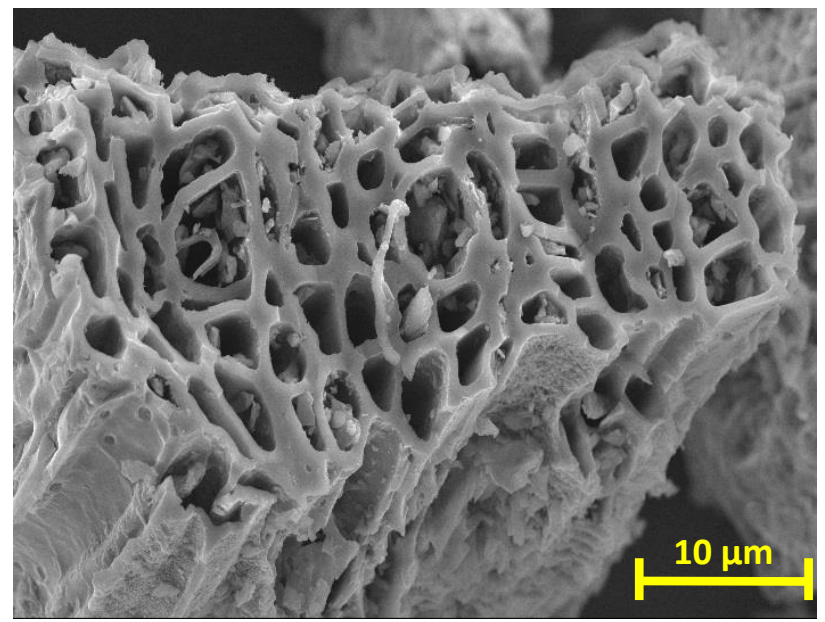

d)

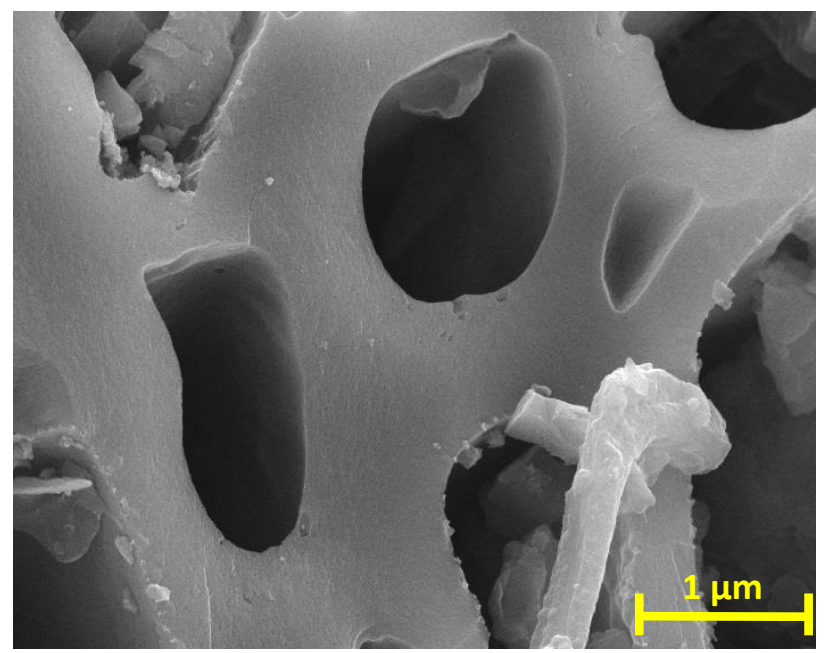

e)

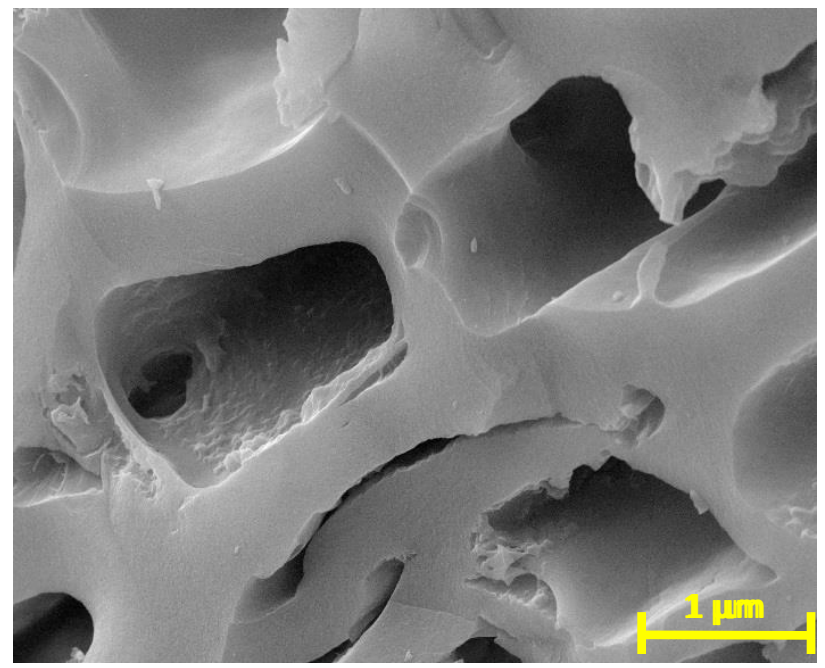

f)

1 Figure 2: SEM images of pomace biomass (a-c) and biochar (d-f) using ETD detector. 
1 Raman spectroscopy as shown in Figure 3 (a) confirms the different carbon allotropes in both

2 samples with two distinct spectra at 1341 and $1580 \mathrm{~cm}^{-1}$, which are attributed to D and G bands,

3 respectively ${ }^{21}$. The $\mathrm{I}_{\mathrm{D}} / \mathrm{I}_{\mathrm{G}}$ ratio was calculated according to the $\mathrm{D}$ and $\mathrm{G}$ bands intensities and

4 was 0.924 , indicating a low degree of a crystalline graphitic structure which is in line with the

5 XRD results in Figure 1. The structure of the pomace is significantly affected by the pyrolysis,

6 where the two bands dramatically decreased in intensity with the pyrolysis temperature, as

7 shown in Figure 3 (a). The surface species of the pomace and biochar were determined using

8 XPS as shown in Figure 3 (b, c for pomace biomass and d, e for biochar). The $\mathrm{C} 1 \mathrm{~s}$ peak for

9 both (Figure 3 (b, d) was mainly at the binding energy of $284.4 \mathrm{eV}$, which is attributed to C-C

10 and C-H bonding. Furthermore, pomace biomass showed a small peak at around $287.2 \mathrm{eV}$,

11 which is attributed to the $\mathrm{C}=\mathrm{O}$ in the carbonyl group, while biochar showed a minor contribution of $\mathrm{N}-\mathrm{C}=\mathrm{O}^{22}$. The oxygen surface species were significantly changed with the pyrolysis as pomace showed mainly oxide $\left(\mathrm{O}^{2-}\right.$ at $\left.530.1 \mathrm{eV}\right)$ and carbonyl oxygen $(\mathrm{C}=\mathrm{O}$ at $528.5 \mathrm{eV}$ ), while biochar showed hydroxide (at $531.1 \mathrm{eV}$ ) and a higher binding energy carbonyl (at $533.4 \mathrm{eV}$ ) along with a minor contribution of gas-phase $\mathrm{CO}_{2}$ at $536.4 \mathrm{eV}$. The results imply that the oxide species decreased during the formation of carbonaceous char and shifted to the higher binding energy of $\mathrm{C}=\mathrm{O}$ in the biochar structure, as seen in Figure 3 (e) ${ }^{23}$. The results also agree with the EDX results, which showed higher alkaline metals present in the biochar structure which may increase the basicity of the structure, hence absorbed $\mathrm{CO}_{2}$ on the surface. Figure S3 shows the XPS of pomace and biochar, where the obvious difference was the presence of potassium (K $2 p)$ peak in the biochar spectra.

The proximate/ultimate analysis in Table 1 , showed that pomace biomass is a good candidate to be used as an energy crop due to its high higher heating value (HHV) of $21.36 \mathrm{MJ} . \mathrm{kg}^{-1}$ compared with other biomass energy crops such as miscanthus with a calorific value of (16.58 MJ.kg $\left.{ }^{-1}\right)^{4}$ which compares well to potato peel waste which showed an HHV of 15.73 MJ.kg-1 
132 . This further supports the claim that the ash leftover from pomace combustion could be used

2 in the fertiliser industry.

3
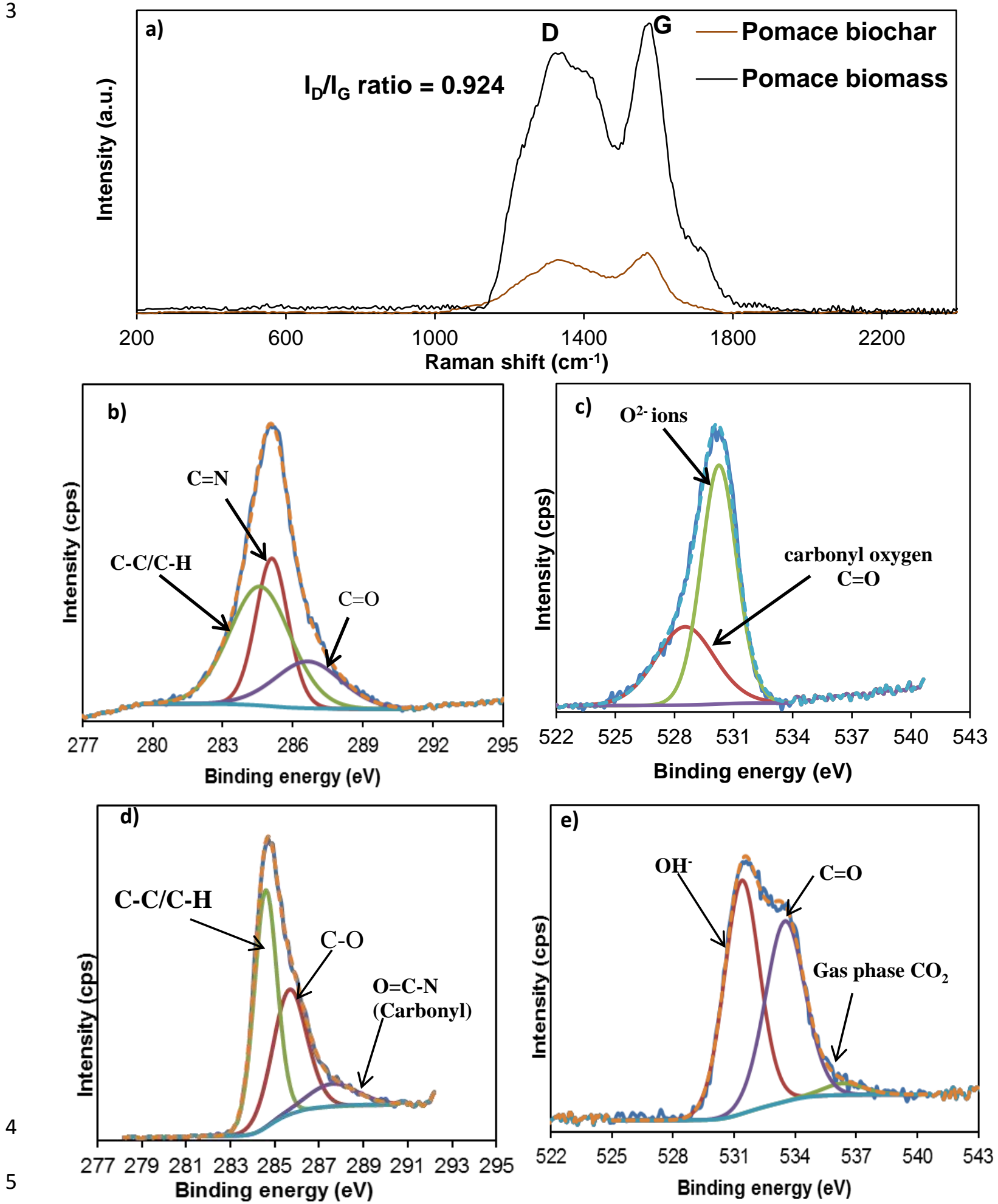

$6 \quad$ Figure 3: a) Raman spectrograms for both pomace biomass and biochar along with the

$7 \quad$ XPS spectra of $\mathrm{C} 1 s$ and $\mathrm{O} 1 s$ for pomace biomass (b, c) and pomace biochar (d, e). 
Table 1: Physicochemical characterisations of pomace biomass waste.

\begin{tabular}{|c|c|c|c|}
\hline \multicolumn{3}{|c|}{ samples } & Pomace biomass \\
\hline \multirow{3}{*}{\multicolumn{2}{|c|}{ Elemental composition }} & $\% \mathrm{C}$ & 48.06 \\
\hline & & $\% \mathrm{H}$ & 6.13 \\
\hline & & $\% \mathrm{~N}$ & 2.60 \\
\hline \multirow{2}{*}{\multicolumn{2}{|c|}{ (wt\% on a dry basis) }} & $\% \mathrm{~S}$ & 0.10 \\
\hline & & $\% \mathrm{O}$ & 43.11 \\
\hline \multirow{3}{*}{\multicolumn{2}{|c|}{ Proximate analysis }} & Moisture & 8.33 \\
\hline & & Volatile & 72.80 \\
\hline & & Char & 27.20 \\
\hline \multirow{4}{*}{\multicolumn{2}{|c|}{ (wt\% on a dry basis) }} & Fixed carbon & 21.70 \\
\hline & & Ash & 3.73 \\
\hline & & $\mathrm{HHV}^{\mathrm{a}}$ & 21.36 \\
\hline & & $\mathrm{LHV}^{\mathrm{b}}$ & 19.57 \\
\hline \multirow{2}{*}{\multicolumn{2}{|c|}{ EDX analysis }} & $\mathrm{C}$ & 71.60 \\
\hline & & $\mathrm{O}$ & 28.40 \\
\hline \multirow{3}{*}{\multicolumn{2}{|c|}{ (wt\% on a dry basis) }} & $\mathrm{K}$ & -- \\
\hline & & $\mathrm{P}$ & -- \\
\hline & & $\mathrm{Mg}$ & -- \\
\hline \multirow{3}{*}{ SBET results } & \multicolumn{2}{|c|}{$\operatorname{SBET}_{\mathrm{BET}}\left(m^{2} \cdot g^{-1}\right)$} & 0.42 \\
\hline & \multicolumn{2}{|c|}{ Pore volume $\left(\mathrm{cm}^{3} \cdot \mathrm{g}^{-1}\right)$} & 0.000005 \\
\hline & \multicolumn{2}{|c|}{ Pore size $\left(\mathrm{A}^{\circ}\right)$} & 18.9 \\
\hline
\end{tabular}

${ }^{a}$ High heating value (kJ. $g^{-1}$ dry feedstock) in $M J . \mathrm{kg}^{-1}$

${ }^{b}$ Low heating value ( $k J . \mathrm{g}^{-1}$ dry feedstock) in MJ.kg-1

\section{Kinetic modelling of pomace combustion}

\section{Differential iso-conversional kinetic model}

\section{AKTS - DSC (Differential Scanning Calorimetry)}

The activation energy and the kinetic parameters of pomace biomass combustion as a solid biofuel were calculated from the DSC curves with different heating rates $\left(2,4,6\right.$ and $8{ }^{\circ} \mathrm{C} \cdot \mathrm{min}^{-}$

${ }^{1}$ ) under air. To ensure the reproducibility of the DSC data, the heating rate of $4{ }^{\circ} \mathrm{C} \cdot \mathrm{min}^{-1}$ was repeated. To have a better understanding of the combustion process of pomace biomass, the AKTS software was employed to calculate the activation energy $\left(E_{a}\right)$ and the pre-exponential factors. Different kinetic modelling methods were utilised such as the ASTM-E698, OzawaFlynn-Wall and differential iso-conversional method such as the Friedman method. As discussed earlier the model-free (iso-conversional) method is preferable than that of the model 
1 fitting method due to various reasons, and in this study, the kinetic parameters were quantified

2 using different heating rates (from $2-8{ }^{\circ} \mathrm{C} \cdot \mathrm{min}^{-1}$ ) as a function of reaction conversion $(\alpha)$.

3 Previous literature studies showed that the mechanism of lignocellulosic biomass combustion

4 is a complicated process that can potentially happen in nine possible parallel reactions at the

5 same time. Pyrolysis, on the other hand, deals with biomass material being converted into

6 products in the three states of matter: solid, liquid and gas ${ }^{24}$. Pyrolysis is the initial physical-

7 chemical processing step which occurs in all thermo-chemical reaction sequences for

8 gasification or combustion. In addition, from biomass, stable liquid hydrocarbons can be

9 produced by the process of liquefaction. This liquefaction process involves the use of low temperatures and high hydrogen pressures, $200-400{ }^{\circ} \mathrm{C}$ and $2-20 \times 10^{6} \mathrm{~Pa}$, respectively ${ }^{3 \mathrm{~b}}$. A proposed ten-step mechanism of pyrolysis is represented as Scheme 1 within the ESI to show the parallel decomposition reactions of cellulose, hemicellulose and lignin in more detail.

In this proposed mechanism, the three different components of biomass (cellulose, hemicellulose and lignin) behave differently and independently to each other with the cellulose separating into active cellulose during the reaction. Despite these components behaving independently, each component pyrolyses to produce char ${ }^{25}$. The degree and classification of the char throughout the mechanism are unknown, unlike the nine-step mechanism as reported by Osman et al. ${ }^{3 \mathrm{~b}}$. Primary gas is produced by pyrolysis of lignin, while primary tar is produced by lignin. As the reaction progresses for each of these components, secondary products are produced, such as secondary gas and secondary tar by pyrolysis of the active cellulose and primary vapours, respectively. The volatile fraction gases are further processed to produce chemicals such as acetone, methanol and recycled back to the pyrolysis reactor to provide heat, while the tar/bio-oil fractions are refined to levoglucosan, acetic acid and automotive fuel ${ }^{25}$.

Thus, a single $E_{a}$ value in either combustion or pyrolysis processes cannot describe the kinetic 
1 parameters accurately ${ }^{3 b, 26}$. Consequently, the iso-conversional method is considered the best

2 method in this case of biomass combustion/pyrolysis.

3 The rate of the thermal decomposition of the pomace biomass can be defined as a function of 4 reaction conversion progress $(\alpha)$ and temperature according to the iso-conversional method.

5 Where $\alpha$ is calculated from the initial, actual and final mass of lignocellulosic biomass.

6 Arrhenius equation which is shown in Table 2 described the temperature-dependent function

7 of the kinetic parameters, i.e. $\mathrm{E}_{\mathrm{a}}$ and pre-exponential factor $\left(\mathrm{k}_{0}\right)$. Thus, as a combination of the

8 rate and Arrhenius equations, the thermal decomposition of pomace biomass can be described 9 as in Eq. 1 below:

$$
\frac{d \alpha}{d t}=k_{0} e^{\left(\frac{-E_{a}}{R T}\right)} f(\alpha) \quad \text { Equation } 1
$$

Usually, the iso-conversional method (non-isothermal) uses different linear heating rates, $\beta=$ $\mathrm{dT} . \mathrm{dt}^{-1}$, and so the thermal process of pomace biomass can be described as in Eq. 2 below:

$$
\frac{d \alpha}{d T}=\frac{k_{0}}{\beta} e^{\left(\frac{-E_{a}}{R T}\right)} f(\alpha)
$$

Equation 2

The non-isothermal iso-conversional methods such as ASTM-E698, Flynn-Wall and Ozawa (FWO) and Kissinger-Akahira-Sunose (KAS) methods are shown in Table 2. While the Friedman method represents the isothermal iso-conversional method in Table 2. 
1 Table 2: shows the non-isothermal and iso-thermal iso-conversional methods used in kinetic

2 modelling.

\begin{tabular}{|c|c|c|}
\hline Methods types & Method Name & Equation \\
\hline \multirow{4}{*}{ Non-Isothermal } & Arrhenius Equation & $\mathrm{k}=\mathrm{k}_{0} \frac{-E a}{R T}$ \\
\hline & ASTM- E698 & $\beta \frac{d \alpha}{d t}=k_{0} e^{\left(\frac{-E_{a}}{R T}\right)}(1-\alpha)$ \\
\hline & $\begin{array}{l}\text { Flynn-Wall and Ozawa } \\
\text { (FWO) }\end{array}$ & $\ln \beta=\ln \left(\frac{k_{0} \cdot E_{a}}{R \cdot g(\alpha)}\right)-5.331-1.052 \frac{E_{a}}{R . T}$ \\
\hline & $\begin{array}{l}\text { Kissinger-Akahira-Sunose } \\
\text { (KAS) }\end{array}$ & $\frac{\ln \beta}{T^{2}}=\ln \left[\frac{k_{0} \cdot R}{E_{a} \cdot g(\alpha)}\left(1-\frac{2 R T}{E_{a}}\right)\right]-\left(\frac{E_{a}}{R \cdot T}\right)$ \\
\hline Isothermal & $\begin{array}{l}\text { Friedman } \\
\text { (Iso-conversional) }\end{array}$ & $\ln \beta \frac{d \alpha}{d T}=\ln \left[k_{0} f(\alpha)\right]-\frac{E_{a}}{R T}$ \\
\hline
\end{tabular}

4 Figures S4 and S5 in ESI show the heat flow of the biomass combustion at different heating 5 rates of 2 and $4{ }^{\circ} \mathrm{C} \cdot \mathrm{min}^{-1}$ (Figure S4) and 6 and $8{ }^{\circ} \mathrm{C} \cdot \mathrm{min}^{-1}$ (Figure S5) where the coloured and black curves are for practical and theoretical data from the simulation, respectively. It is not surprising that there was a significant shift in the ignition temperature by $49{ }^{\circ} \mathrm{C}$ between the lowest and the highest heating rates. The burnout temperature showed an even higher shift by $88{ }^{\circ} \mathrm{C}$, as shown in Figure S6. The decomposition temperature at a low heating rate, i.e. 2 ${ }^{\circ} \mathrm{C} . \mathrm{min}^{-1}$ was in the temperature range of $194.8-557^{\circ} \mathrm{C}$, while at a high heating rate $\left(8^{\circ} \mathrm{C} . \mathrm{min}^{-}\right.$ ${ }^{1}$ ) was in the range of $244-645^{\circ} \mathrm{C}$. This shift in the decomposition stages along with the increase in the heating rates are due to the combined effects of heat transfer and the kinetics of decomposition of waste berry pomace. This combination effects result in delaying the thermal decomposition of waste berry pomace, thus by increasing the heating rates from 2 to $8^{\circ} \mathrm{C}$. $\mathrm{min}^{-}$ ${ }^{1}$, has led to shortening the time required for the pomace biomass to reach a given temperature, thus leading to mass transfer limitation within the process and delay the decomposition to the higher reaction temperatures. There is a probability of temperature gradients that may exist 
1 within the sample, and thus devolatilization rate will be faster than the volatile release, and

2 consequently, various devolatilization stages may occur ${ }^{27}$. These results are in agreement with

3 the work reported in the literature such as Wang et al. ${ }^{28}$, Unapumnuk et al. ${ }^{29}$ and Chen et al. $4 \quad 27$.

$5 \quad$ Figures S4 and S5 show that the peak height was shifted from 0.5 to $5.5 \mathrm{~W} . \mathrm{g}^{-1}$ by increasing 6 the heating rates from 2 to $8{ }^{\circ} \mathrm{C} \cdot \mathrm{min}^{-1}$.

7 The conversion $(\alpha)$ versus temperature for the pomace combustion is shown in Figure 4 with 8 coloured curves for the practical results, while black-dashed curves for the theoretical 9 calculations by AKTS software. Overall, there was a distinct match between the practical and 10 theoretical calculations with $\mathrm{R}^{2}=0.9907$. All of the experimental results fit the same shape for reaction progress, with the highest heating rate $\left(8{ }^{\circ} \mathrm{C} \cdot \mathrm{min}^{-1}\right)$ being the furthest right curve and the lowest heating rate $\left(6^{\circ} \mathrm{C} \cdot \mathrm{min}^{-1}\right)$ being the furthest left curve, respectively.

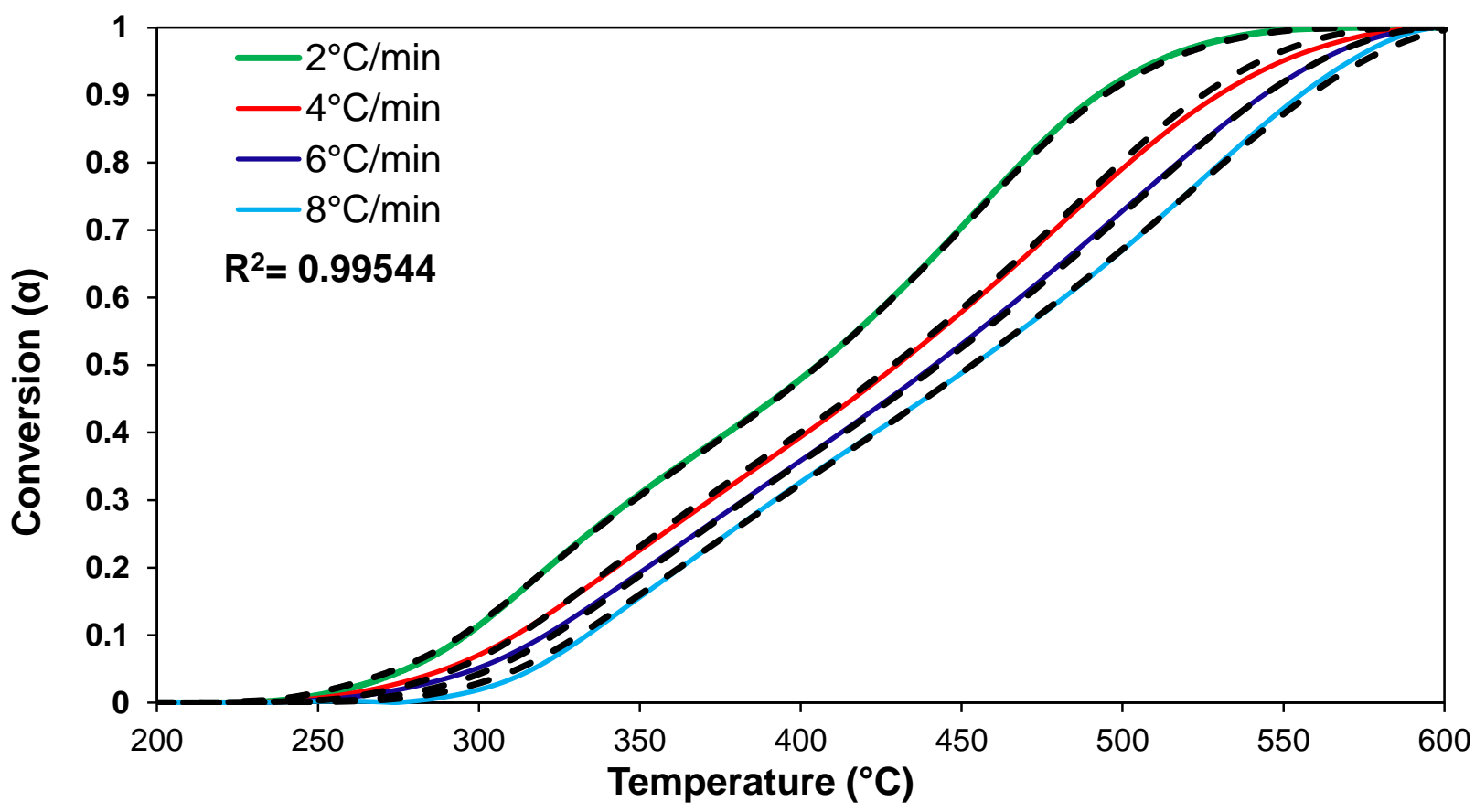

Figure 4: Conversion $(\alpha)$ versus the temperature for the pomace biomass combustion where the coloured and dashed black curves show the practical and theoretical calculations, respectively. 
1 Figure 5 shows the reaction rate versus the temperature for the pomace biomass combustion

2 where the coloured and dashed black curves show the practical and theoretical calculations,

3 respectively. Again, there is a perfect match at lower heating rates, i.e. $2-6{ }^{\circ} \mathrm{C} \cdot \mathrm{min}^{-1}$, while at 8

$4{ }^{\circ} \mathrm{C} \min ^{-1}$, there was slight deviation which may be due to the large amount of heat generated

5 from the combustion process at $8{ }^{\circ} \mathrm{C} \cdot \mathrm{min}^{-1}$. This result is in line with other work that showed

6 the same trend at high heating rate ${ }^{3 b}$. Furthermore, the theoretical and practical results both

7 showed a clear shift toward higher temperature with increasing the heating rate from 2 to 8

$8{ }^{\circ} \mathrm{C} \cdot \mathrm{min}^{-1}$. The first decomposition peak appeared at 303, 323, 330 and $341{ }^{\circ} \mathrm{C}$ at heating rates

9 of $2,4,6$ and $8{ }^{\circ} \mathrm{C} \cdot \mathrm{min}^{-1}$, respectively. While the second decomposition peak was present at $10463,502,518$ and $533{ }^{\circ} \mathrm{C}$ at heating rates of $2,4,6$ and $8{ }^{\circ} \mathrm{C} \cdot \mathrm{min}^{-1}$, respectively. The maximum

11 reaction rate for all the heating rates tested occurred at the second decomposition peak.

12 Subsequently, the maximum reaction rates were found to be $0.000164,0.000301,0.000427$ and $0.000578 \mathrm{~s}^{-1}$ for $2,4,6$ and $8{ }^{\circ} \mathrm{C} \cdot \mathrm{min}^{-1}$, respectively. The reaction rate increased six times by increasing the heating rate from 2 to $8{ }^{\circ} \mathrm{C} \mathrm{min}^{-1}$, as seen in Figure 5. The results are in agreement with the work done by Kumar et al. ${ }^{30}$. 


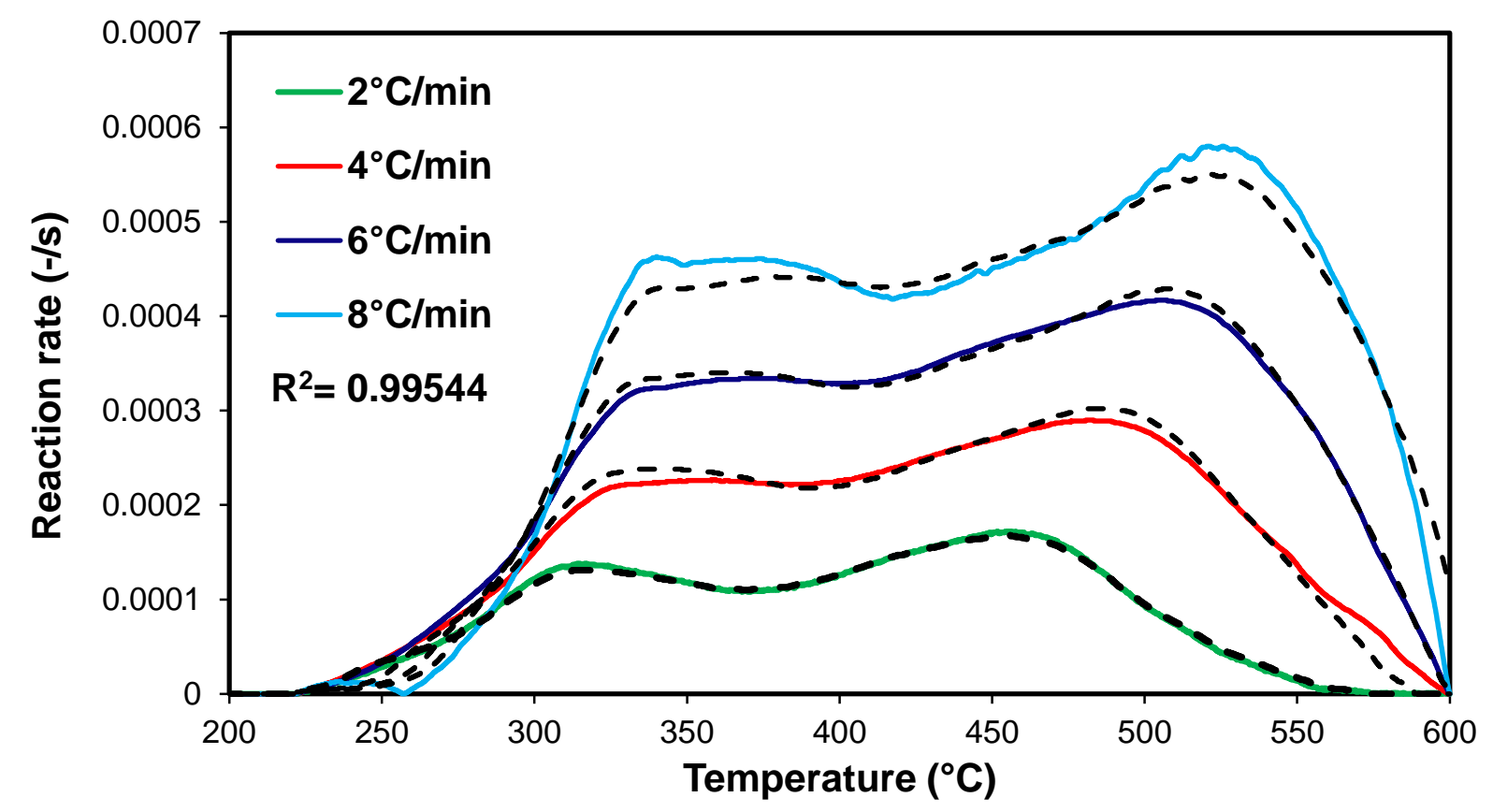

2 Figure 5: Reaction rate versus the temperature for the pomace biomass combustion where the 3 coloured and dashed black curves show the practical and theoretical calculations, respectively.

$4 \quad$ Kinetic modelling discussion of pomace combustion (DSC)

6 In general, lignocellulosic biomass shows three decomposition stages during the thermal decomposition. Similar biomass to the berry pomace used, such as olive pomace showed three distinct thermal decomposition zones. The first zone was the drying and evaporation of water up to $150{ }^{\circ} \mathrm{C}$. This is closely followed by phase two, the devolatilisation of hemicellulose and cellulose at $150-400{ }^{\circ} \mathrm{C}$, while lignin was decomposed in phase three at $400-800{ }^{\circ} \mathrm{C}{ }^{31}$. Similarly, the thermal degradation behaviour of grape pomace in an inert atmosphere exhibited at temperatures below $130{ }^{\circ} \mathrm{C}$, there was a slight loss of weight due to evaporation of moisture and volatilisation of small organic molecules. Decomposition of hemicellulose occurred around $200{ }^{\circ} \mathrm{C}$ and reached the maximum weight loss rate at $273{ }^{\circ} \mathrm{C}{ }^{32}$. The hemicellulose decomposition overlapped with cellulose decomposition as like the olive pomace, however, the greatest cellulose breakdown occurred at 300 to $320^{\circ} \mathrm{C}$. Lignin was the final component to 
1 decompose at approximately $100{ }^{\circ} \mathrm{C}$ in excess of the cellulose at $420^{\circ} \mathrm{C}$. The main degradation

2 occurs at temperatures between 200 and $483{ }^{\circ} \mathrm{C}{ }^{32}$. Thus, due to the complexity of pomace

3 thermal decomposition, it is not feasible to represent the kinetic parameters with the model-

4 fitting approach nor a single activation energy value for that complicated process. Again, due

5 to the complexity of the lignocellulosic biomass decomposition, one single $E_{a}$ value is

6 inadequate to define the thermal decomposition; thus, the ASTM-E698 method is imprecise

7 herein. Hence, the iso-conversional method is used herein to calculate the kinetic parameters

$8 \quad\left(\mathrm{E}_{\mathrm{a}}\right.$ and $\left.\mathrm{K}_{0}\right)$ as a function of $\alpha^{33}$.

9
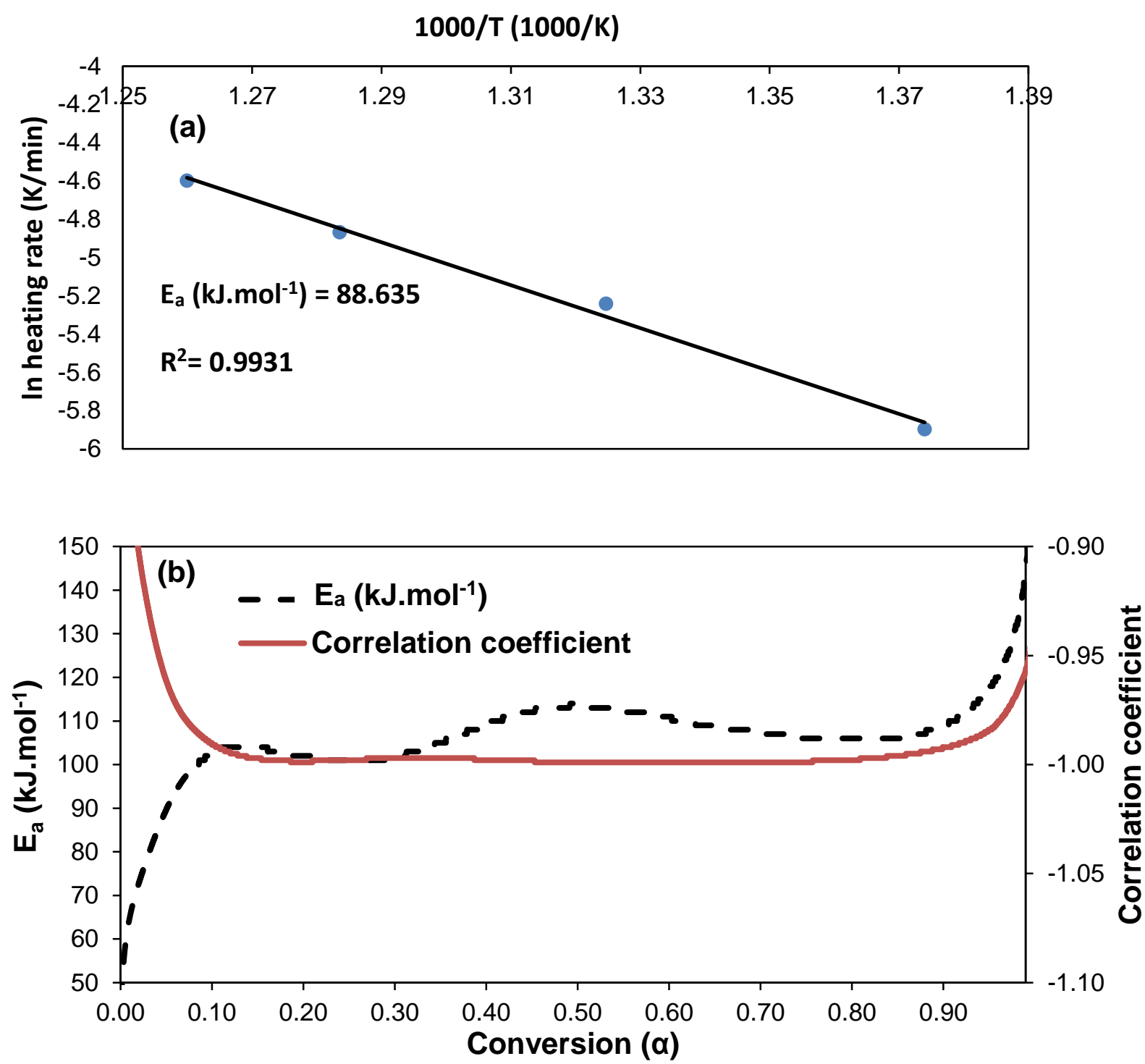

Figure 6: Kinetic parameters calculated by different methods (a) $E_{a}$ using the ASTM-E698 method and (b) $E_{a}$ and pre-exponential factor using the Flynn-Wall and Ozawa (FWO) method. 
1 Figure 6 (b) shows the activation energy calculated using Flynn-Wall and Ozawa method

2 (FWO), which is more accurate than that of ASTM-E698 method as the $\mathrm{E}_{\mathrm{a}}$ is changing during

3 the reaction progress. The $\mathrm{E}_{\mathrm{a}}$ showed values in the range of $50-140 \mathrm{~kJ}^{\mathrm{mol}}{ }^{-1}$ during the reaction

4 progress. Horse and cattle manure which have been previously studied to show that horse

5 manure combustion has activation energies within the ranges of $176.2-293.6 \mathrm{~kJ} \cdot \mathrm{mol}^{-1}, 175.6-$

$6300.1 \mathrm{~kJ} \cdot \mathrm{mol}^{-1}$ and $170.2-244.1 \mathrm{~kJ}^{-\mathrm{mol}^{-1}}$ for the methods of FWO, KAS and Friedman,

7 respectively. Whilst dried cattle manure has a larger $\mathrm{E}_{\mathrm{a}}$ range from $119-348 \mathrm{~kJ}^{\mathrm{mol}}{ }^{-1}$, however,

8 in comparison, the $E_{a}$ from the dried material is close to the range of activation energy from

9 fresh cattle manure with the respect that both cattle and horses are grass-grazing herbivores ${ }^{34}$.

10 Moreover, with the aid of AKTS software, the kinetic parameters were calculated with the

11 differential iso-conversional method, as shown in Figure $7(a, b)$. The natural logarithm of the reaction rate in $\left(\mathrm{s}^{-1}\right)$ versus the inverse temperature is shown in Figure 7 (a), while the calculated $E_{a}$ and $K_{0}$ are shown in Figure 7 (b). At the beginning of the thermal decomposition where $\alpha=$ 0 , the $\mathrm{E}_{\mathrm{a}}$ was $84.3 \mathrm{~kJ} \cdot \mathrm{mol}^{-1}$ then quickly declined to $76.8 \mathrm{~kJ} \cdot \mathrm{mol}^{-1}$ as the $\alpha$ was 0.01 . The $\mathrm{E}_{\mathrm{a}}$ value then gradually increased to $108.4 \mathrm{~kJ} \mathrm{~mol}^{-1}$ as $\alpha$ reached 0.05 , followed by a gradual decrease to $92 \mathrm{~kJ} \mathrm{~mol}^{-1}$ when $\alpha$ was 0.2 . Then the $\mathrm{E}_{\mathrm{a}}$ values showed a variation during the reaction with values of 113,95 and $188 \mathrm{~kJ} \mathrm{~mol}^{-1}$ as the reaction proceeded with $\alpha$ values of 0.4 , 0.7 and 1 , respectively. Hence, the differential iso-conversional method showed the most realistic values for the kinetic parameters than other methods, along with demonstrating the presence of numerous reactions during the pomace biomass thermal decomposition. 


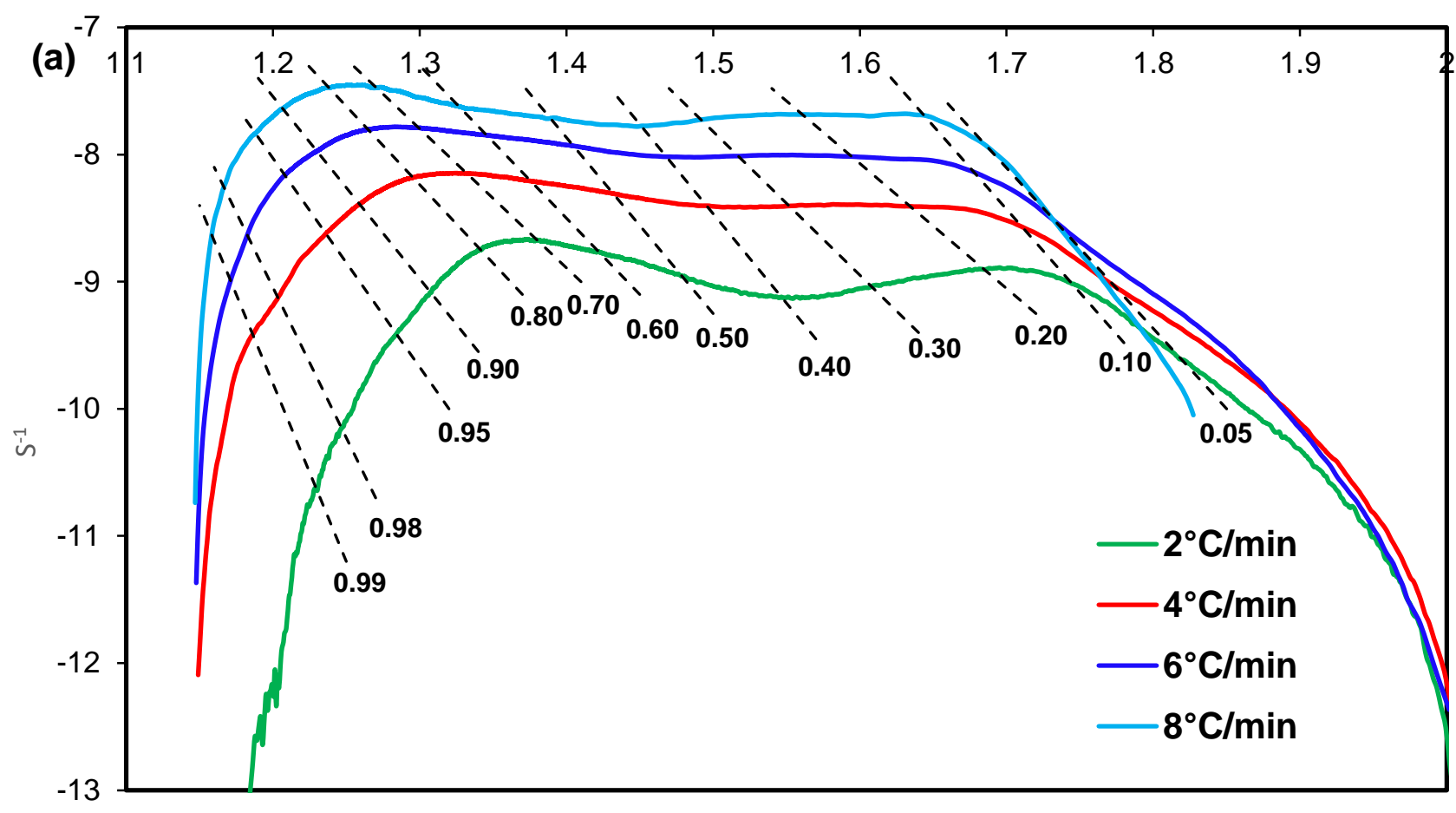

1
2
3
4
5
6

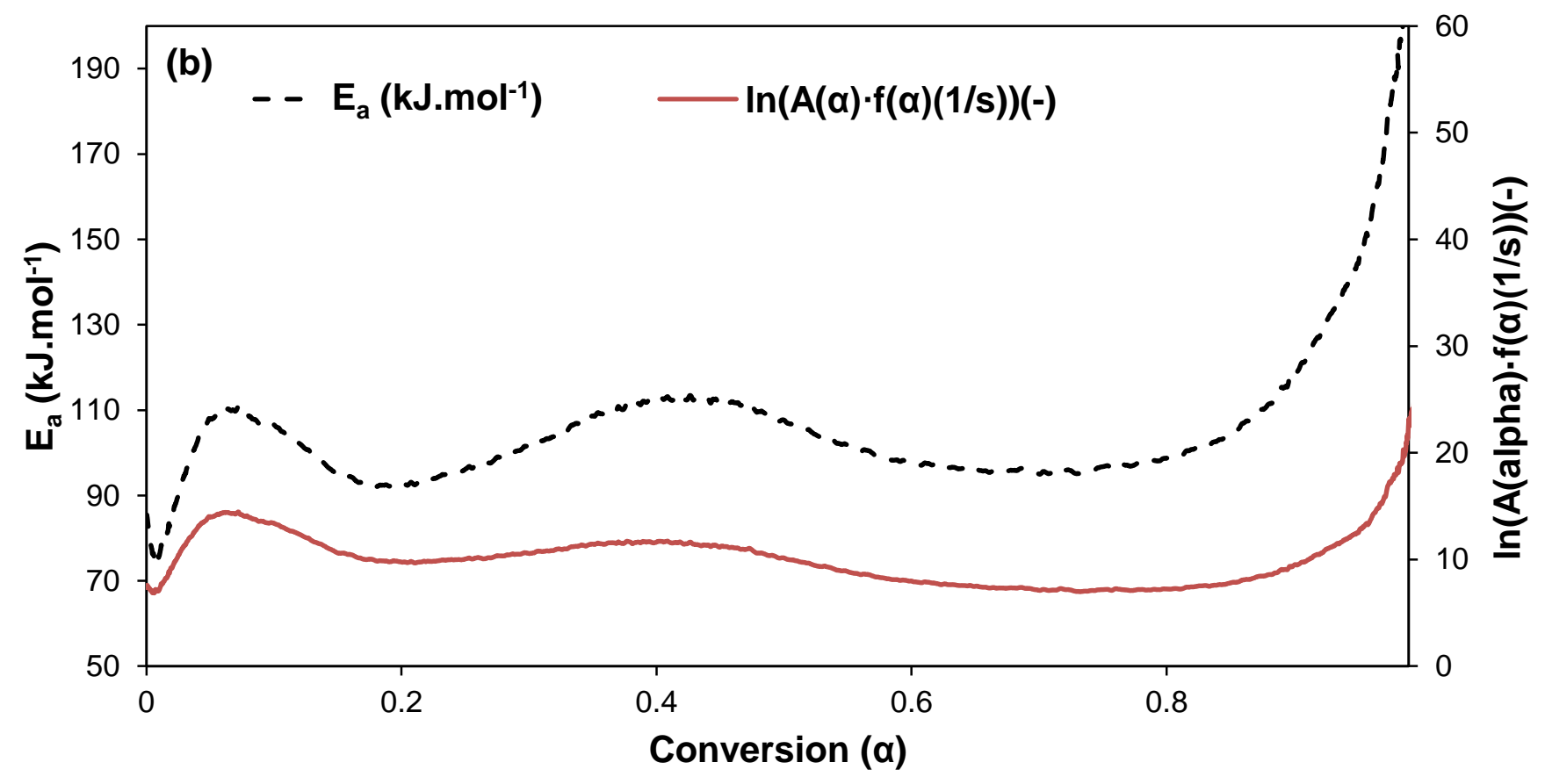

Figure 7: Combustion kinetic parameters calculated with the differential iso-conversional method, a) natural logarithm of the reaction rate in $\left(\mathrm{s}^{-1}\right)$ versus the inverse temperature, $\left.b\right) \mathrm{E}_{\mathrm{a}}$ and $\ln \mathrm{k}_{0}$. 


\section{Prediction of Combustion Behaviour using Isothermal Model}

2

The kinetic prediction of isothermal combustion of pomace biomass produced using AKTS software is shown in Figure 8 (a). It is evident that a temperature higher than $500{ }^{\circ} \mathrm{C}$ is required in order to complete the reaction within 60 minutes reaction time. At a temperature of $400{ }^{\circ} \mathrm{C}$ for a reaction time of 60 minutes, the reaction progress was only $68 \%(\alpha=0.68)$, while at $460^{\circ} \mathrm{C}$, the reaction progress had increased to $91 \%$ within the same reaction time. At temperatures of $560{ }^{\circ} \mathrm{C}$ and $600^{\circ} \mathrm{C}$, the reaction had achieved $100 \%$ completion $(\alpha=1)$ after 30 and 6 minutes, respectively. This simulation profile of isothermal combustion of berry pomace is comparative with other lignocellulosic material as reported in the miscanthus study ${ }^{3 b}$. The reported heat

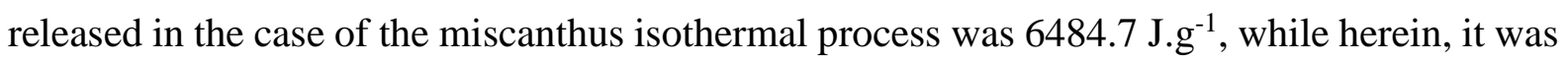

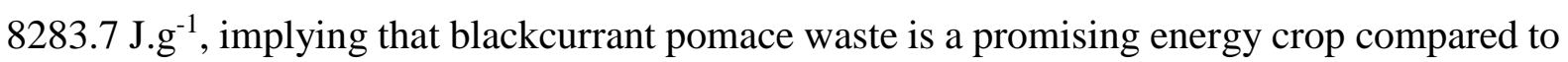
other biomass energy crops. This is not surprising when considering the calorific value of the berry pomace is marginally higher $\left(21.36 \mathrm{MJ} \cdot \mathrm{kg}^{-1}\right)$ than that of miscanthus $\left(16.58 \mathrm{MJ} \cdot \mathrm{kg}^{-1}\right)^{16 \mathrm{~b}}$.

Figure 8 (b) shows the maximum heat release rate at temperatures $400-600{ }^{\circ} \mathrm{C}$. As the temperature increases, the max heat release rate increases exponentially, which fits the trend of increasing temperature will increase the amount of heat liberated. The increase in the maximum heat release with increasing the isothermal temperature is due to the heat transfer limitation, and heat provided by the isothermal operation and linked to point no. 3 . The heat provided at a lower temperature condition such as $400^{\circ} \mathrm{C}$, is mainly consumed to overcome the activation energy of the decomposition of waste berry pomace. While at a higher isothermal temperature such as $600^{\circ} \mathrm{C}$, part of the heat is consumed within the reaction process and the excess heat is released along with the exothermic nature of the combustion reaction. Given also the time required for reaction completion $(\alpha=1)$, the temperature condition reached this point at a significantly shorter time compared to that of lower temperature conditions. For 
1 instance, at a reaction temperature of $400^{\circ} \mathrm{C}$, time of $220 \mathrm{~min}$ is required for $\alpha=1$, while at a

2 reaction temperature of $600^{\circ} \mathrm{C}$, a mere 7 minutes is needed. This is in agreement with the work

3 done by Mouritz et al., who reported a similar trend of the maximum heat release ${ }^{35}$.

4 From the temperatures chosen, the maximum percentage increase between each step occurs

5 from $400-420^{\circ} \mathrm{C}$, in which the heat liberated increases by $98.3 \%$ compared to the result at 400

$6{ }^{\circ} \mathrm{C}$. There is a drastic increase in the max heat release rate from $540{ }^{\circ} \mathrm{C}$ onwards, in which these

7 temperatures $\left(540,560,580\right.$ and $\left.600{ }^{\circ} \mathrm{C}\right)$ all exceed $4000 \mathrm{~W} \cdot \mathrm{g}^{-1}$. The maximum difference in 8 max heat release rate occurs in the final step from $580-600{ }^{\circ} \mathrm{C}$.

9

10 

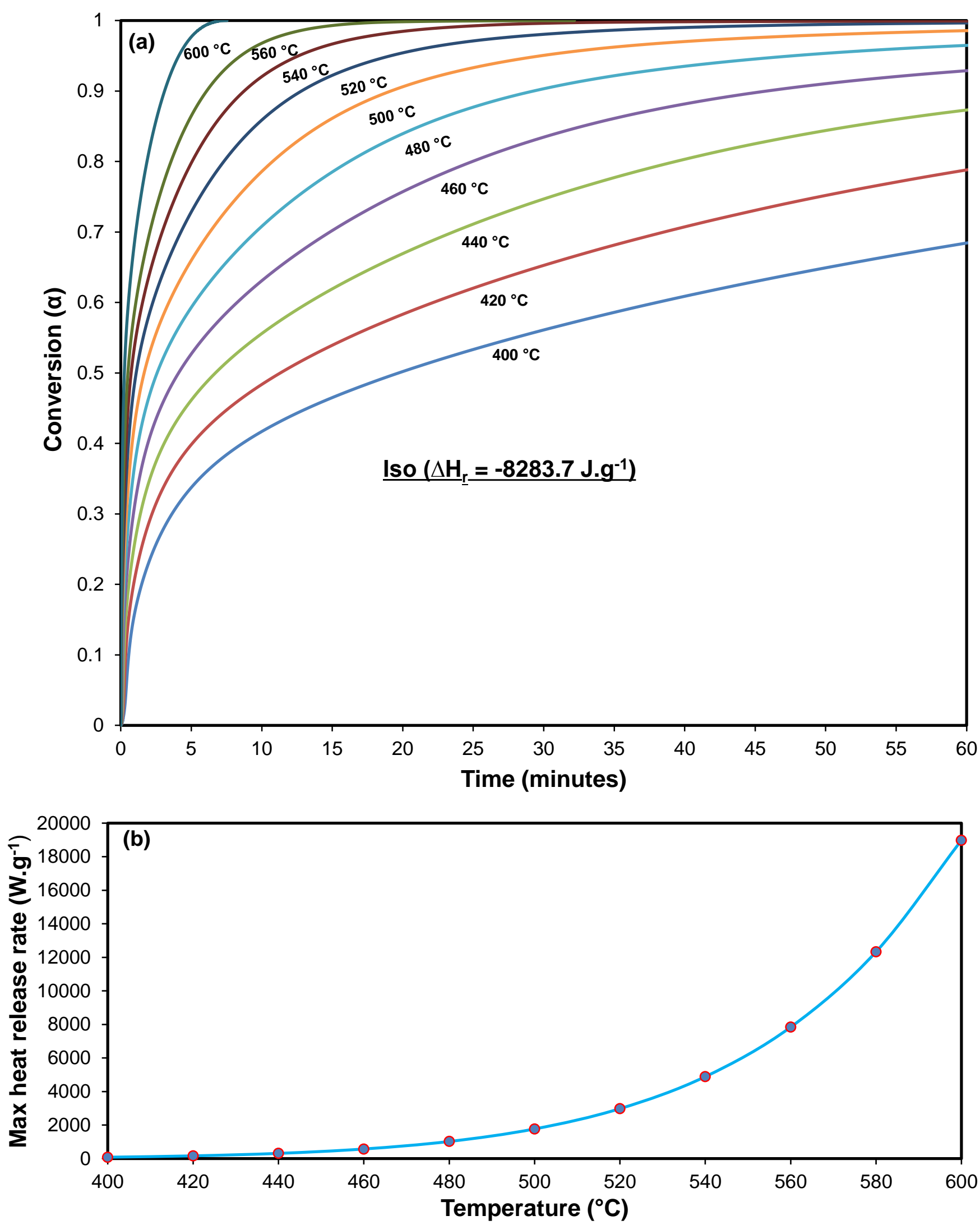

1 Figure 8: Predicted behaviour of pomace biomass using AKTS software under iso-thermal

2 conditions, a) isotherms showing a change in reaction progress in the temperature range of 400-

$3600{ }^{\circ} \mathrm{C}, \mathrm{b}$ ) maximum heat release rate of temperatures $400-600{ }^{\circ} \mathrm{C}$. 


\section{Prediction of Combustion Behaviour using Non-isothermal Model}

Figure 9 below illustrates the prediction of non-isothermal combustion of the lignocellulose material using AKTS over four different, substantially higher heating rates of 20, 50, 75 and $100{ }^{\circ} \mathrm{C} . \mathrm{min}^{-1}$ up to a maximum temperature of $600{ }^{\circ} \mathrm{C}$. The reaction progress is denoted by dashed lines, and the reaction rate is denoted by solid lines. This prediction profile is quantified with the rate of reaction and reaction progress for each predicted heating rate. For the 20 ${ }^{\circ} \mathrm{C} . \mathrm{min}^{-1}$ heating rate, the maximum rate of reaction was $0.00122 \mathrm{~s}^{-1}$ at a temperature of $573{ }^{\circ} \mathrm{C}$ and reaction progress of approximately 0.78 . At $50{ }^{\circ} \mathrm{C} \cdot \mathrm{min}^{-1}$, the maximum rate of reaction was $0.00262 \mathrm{~s}^{-1}$ at $498^{\circ} \mathrm{C}$, corresponding at reaction progress of approximately 0.41 . At 75 and 100 ${ }^{\circ} \mathrm{C} \cdot \mathrm{min}^{-1}$, the maximum rates of reaction were 0.00391 and $0.00538 \mathrm{~s}^{-1}$ at 394 and $404{ }^{\circ} \mathrm{C}$, respectively, with reaction progress of approximately 0.08 . It is clear that increasing the heating rate, the maximum rate of reaction shifts upwards with every increase in temperature, as shown in Figure 9. An interesting trend of this particular reaction profile is that when the heating rate is increased, the alpha corresponding to the maximum rate of reaction is lowered for all of the heating rates. This shifting phenomenon is found in various other sources of biomass when under non-isothermal conditions such as the DTG profiles at four different heating rates of South African coals, thermal decomposition of corncob and rice husks under non-isothermal conditions ${ }^{36}$. Considering the non-isothermal reaction rates in comparison to the initial heating rates tested via DSC signals, the reaction rates appear to be substantially higher in the nonisothermal; predictions. This is to be expected with higher heating rates. For example, taking the lowest heating rates in both sections, the maximum reaction rate of $0.00122 \mathrm{~s}^{-1}$ at $20^{\circ} \mathrm{C} . \mathrm{min}^{-}$ ${ }^{1}$ in the non-isothermal prediction, is approximately seven times higher than that of 0.000164 $\mathrm{s}^{-1}$ at $2{ }^{\circ} \mathrm{C} \cdot \mathrm{min}^{-1}$. On the other hand, at the highest heating rates in both sections, the maximum reaction rate of $0.00538 \mathrm{~s}^{-1}$ at $100{ }^{\circ} \mathrm{C} \cdot \mathrm{min}^{-1}$ in the non-isothermal prediction, is approximately nine times higher than that of $0.000578 \mathrm{~s}^{-1}$ at $8^{\circ} \mathrm{C} \cdot \mathrm{min}^{-1}$. 
1 Using both isothermal and non-isothermal predictions can help inform multiple audiences such

2 as academia and industry. For example, non-isothermal predictions with the inclusion of a

3 ramp/heating rate are more likely to describe and benefit an industrial setting. Whereas the

4 isothermal prediction can be used for both audiences. With the isothermal prediction plot, the

5 point at which diminishing returns may occur in the combustion of waste berry pomace can be

6 seen from the isotherms. Identifying optimum operating parameters such as temperature or

7 heating rate will have a positive influence on process engineering.

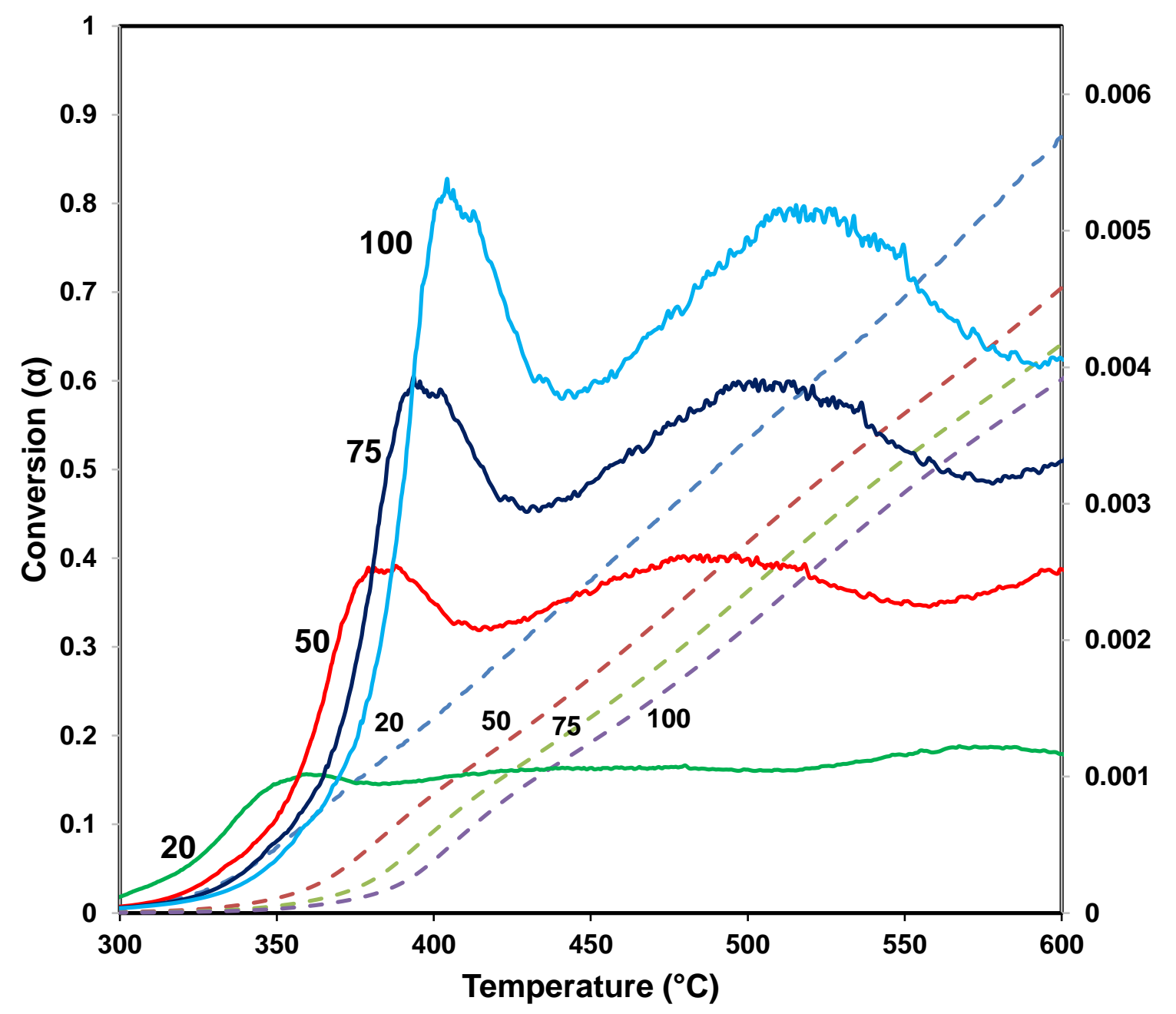

$9 \quad$ Figure 9: Predicted behaviour of pomace biomass combustion using the non-isothermal 10 model at higher heating rates of $25,50,75$ and $100{ }^{\circ} \mathrm{C} \cdot \mathrm{min}^{-1}$ using AKTS software. 


\section{Validation of combustion kinetics using TGA/DTG}

2 In order to validate the results of the kinetic parameters obtained from AKTS, a second set of thermo-analytical data in the form of TGA/DTG results was used to determine the reaction parameters and compare with the original results obtained via DSC signals ${ }^{37}$. The TGA results were first imported into AKTS, and then the DTG profiles were made prior to the baseline construction in order to integrate the DTG result with respect to the combustion reaction profile. The baseline types used for the TGA results were spline and tangential first point, depending on the signal. The practical curves, their integration, and the subsequent simulated results from the TGA kinetic modelling results at different heating rates are shown in Figure S7 and S8 in ESI. Like the DSC results, it showed a good match between the theoretical and kinetic modelling with $\mathrm{R}^{2}=0.99194$. Furthermore, the time required for the thermal decomposition was significantly reduced with increasing the heating rates. For example, the heating rates of $2,4,6$ and $8{ }^{\circ} \mathrm{C} \cdot \mathrm{min}^{-1}$ showed a decomposition time range of 2037-17100, $1411-8625,891-5700$ and 669-4275 s, respectively.

The result from the integrated DTG profiles was that on average the pomace lost $80.91 \pm 3.7$ wt.\% of its mass when considering the four imported heating rates. The $\mathrm{R}^{2}$ was found to be slightly lower than that of the DSC based model (99.194\% as opposed to $99.544 \%$ ), but still highly accurate, however. The kinetic parameters were found to be similar for both the DSC and TGA results. Therefore only the reaction progress and the reaction rates of 2, 4, 6 and 8 ${ }^{\circ} \mathrm{C} . \mathrm{min}^{-1}$ in terms of temperature were included in this section as Figure $10(\mathrm{a}, \mathrm{b})$ below. When considering the maximum rate of reactions, the TGA based results were found to be 0.000173 , $0.000338,0.00048$, and $0.00067 \mathrm{~s}^{-1}$ for $2,4,6$ and $8{ }^{\circ} \mathrm{C} . \mathrm{min}^{-1}$. This was opposed to 0.000164 , $0.000301,0.000427$, and $0.000578 \mathrm{~s}^{-1}$ that were reported for the DSC results of the same heating rates. It is worth noting that these maximum reaction rates that occur along the reaction progress are very similar and do not deviate much (down to 4-5 decimal places). 

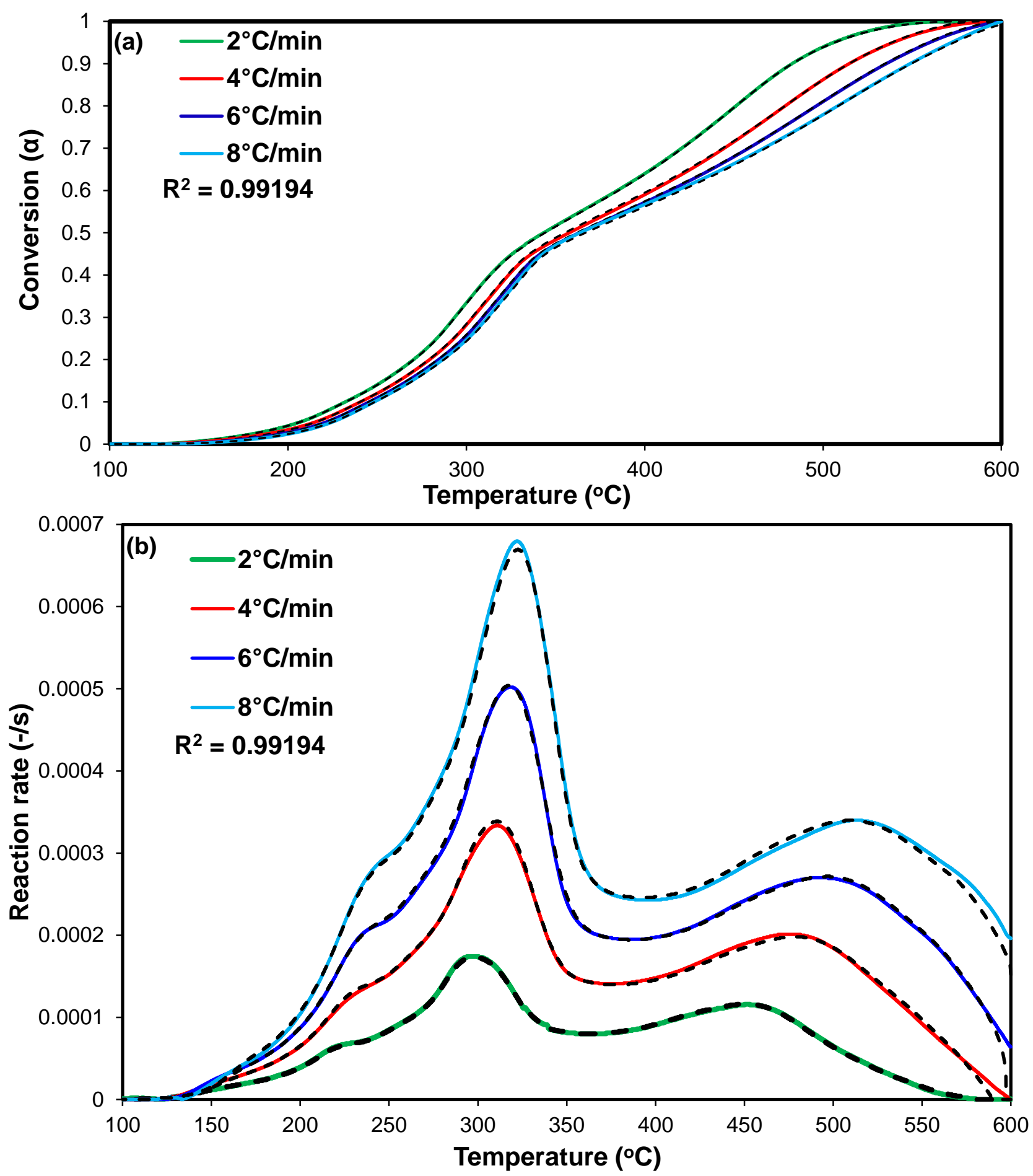

3 Figure 10: shows a) the reaction conversion $(\alpha)$ and b) reaction rate versus the temperature for

4 the pomace biomass combustion using TGA data where the coloured and dashed black curves

5 show the practical and theoretical calculations, respectively.

6 


\section{Comparison of combustion and thermal degradation behaviour of pomace}

2

3

4

Figure S9 (a) shows the $E_{a}$ calculated according to ASTM-E69 method with a value of 89.12 $\mathrm{kJ} . \mathrm{mol}^{-1}$. On the other hand, the FWO method showed a variation of $\mathrm{E}_{\mathrm{a}}$ during the reaction progress or the conversion in the range of $84-220 \mathrm{~kJ}^{\mathrm{mol}}{ }^{-1}$, as shown in Figure S9 (b). The differential iso-conversional method in Figure S10 was used to calculate the $\mathrm{E}_{\mathrm{a}}$ of pomace combustion, which showed a variation in the $E_{a}$ value in the range of 81.9-206.0 kJ.mol ${ }^{-1}$. The reported average $\mathrm{E}_{\mathrm{a}}$ value of corn stover thermal decomposition with FWO and KAS models are $191.6 \mathrm{~kJ} \mathrm{~mol}^{-1}$ and $181.7 \mathrm{~kJ} \cdot \mathrm{mol}^{-1}$, respectively ${ }^{38}$. The thermal decomposition of corn stock, a by-product of the agriculture harvesting of corn for human and animal feed production has been studied by Cai et al. over a range of conversion factors performed by TGA at five heating rates. As the conversion factors range from 0.05 to 0.85 , the activation energies also vary from $148-473 \mathrm{~kJ} \cdot \mathrm{mol}^{-1}$. Osman et al. reported that the activation energies for miscanthus varied from $40-165 \mathrm{~kJ} \mathrm{~mol}^{-1}$ via the differential iso-conversional method throughout the progress of the reaction ${ }^{3 b}$. This is attributed to the different thermal kinetic behaviours of the lignocellulosic components ${ }^{39}$. Due to the limited number of kinetic studies of the combustion of berry pomace, a comparison of other biomass feedstocks has been noted below. As previously studied by Mong et al. for the kinetic study of horse manure, the FWO and KAS methods produced an $E_{a}$ of $148.47 \mathrm{~kJ} \mathrm{~mol}^{-1}{ }^{40}$. Similarly, Otero et al. produced an $\mathrm{E}_{\mathrm{a}}$ of 212 $\mathrm{kJ} \mathrm{mol}^{-1}$ via the FWO method for cattle manure ${ }^{34}$. Ultimately when considering the combustion of berry pomace, there is a clear possibility for a transition to a circular economy as the pomace is initially a spent waste material from the food and drinks sector that can be used as an energy resource ${ }^{41}$. This study aimed to investigate the concept of how to convert this wasteful and valueless material into that of higher value. For example, its high calorific value for energy production, the use as biochar product as an adsorbent in wastewater treatment and the potential extraction of a bio-oil during the production of biochar. Therefore, the material which was once 
1 disposed of for composting and in some cases sent to landfill has now been given the potential

2 of making added-value products and may find one of many uses outlined in this study.

\section{Conclusion}

4

5 The physicochemical characterization of berry pomace waste biomass and its thermochemical

6 products along with the evaluation of the kinetic triplet concerning combustion of berry pomace

7 were performed using thermo-analytical data (DSC and TGA/DTG). Pomace biomass waste

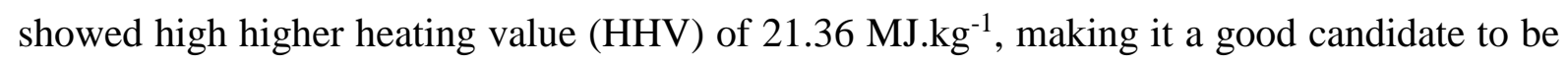
used in energy application compared with other biomass energy crops. Pomace ash showed high potassium content of $28.5 \mathrm{wt} . \%$, making the ash a valuable fertilizer for agriculture postcombustion. The kinetic model was constructed utilizing a model-free method using DSC, validated using TGA, and both, isothermal and non-isothermal predictions were made at higher heating rates to represent a realistic scenario that would occur. The activation energies were also evaluated using the ASTM-E698 (88.64 and $89.12 \mathrm{~kJ} \cdot \mathrm{mol}^{-1}$ from DSC and TGA results, respectively) and Ozawa-Flynn-Wall (50-140 $\left.\mathrm{kJ} \cdot \mathrm{mol}^{-1}\right)$ methods. The $\mathrm{R}^{2}$ value of the individual heating rates for DSC and TGA were 0.99544 and 0.99194, respectively. The differential isoconversional method showed activation energy values in the range $84-197 \mathrm{~kJ} . \mathrm{mol}^{-1}$ for pomace combustion. The AKTS combustion model was created herein and validated numerically. This method of construction, validation, simulation, optimization and then finally, prediction of the differential iso-conversional model using AKTS can be applied to other problematic feedstocks and domains of thermochemical conversion such as pyrolysis. Future work will focus on emissions of combustion of berry pomace or its pyrolysis, and potential utilization of the pyrolytic products can be explored. This will help to facilitate concepts such as the circular economy and sustainability in the food and drinks sector. 
1 Acknowledgement: The authors would like to acknowledge the support given by the EPSRC

2 project. AO wish to acknowledge the support of The Bryden Centre project (Project ID

3 VA5048) and the Renewable Engine project (Project ID IVA5033) which was awarded by The

4 European Union's INTERREG VA Programme, managed by the Special EU Programmes

5 Body (SEUPB), with match funding provided by the Department for the Economy in Northern

6 Ireland and the Department of Business, Enterprise and Innovation in the Republic of Ireland.

7 The authors are grateful to South West College and the Centre for Renewable and Sustainable

8 Technology (CREST) for the use of AKTS and the bomb calorimeter. The authors would like

9 to thank Mr. Patrick McNicholl for proofreading the manuscript. The authors acknowledge the

10 support given by the School of Chemistry and Chemical Engineering, Queen's University

11 Belfast and Elmgrove Foods Ltd.

Disclaimer: The views and opinions expressed in this paper do not necessarily reflect those of the European Commission or the Special EU Programmes Body (SEUPB).

Competing financial interests: The author declares no competing financial interests.

\section{AUTHOR INFORMATION}

\section{Corresponding Author}

Dr Ahmed I. Osman - School of Chemistry and Chemical Engineering, Queen's University, David Keir Building, Stranmillis Road, Belfast BT9 5AG, Northern Ireland, United Kingdom. Fax: +44 289097 4687, Tel.: +44 289097 4412. Email: $\underline{\text { aosmanahmed01@qub.ac.uk }}$

ORCID: https://orcid.org/0000-0003-2788-7839

\section{Supporting Information:}

The Supporting Information is available free of charge at

SEM images of pomace ash at different magnification levels using BSED (Figure S1). EDX data of pomace biomass (a), pomace biochar (b) and pomace ash (c) (Figure S2). XPS surveys 
of pomace biomass (top) and pomace biochar (bottom) (Figure S3). Heat flow of the pomace biomass combustion with heating rates $2{ }^{\circ} \mathrm{C} \cdot \mathrm{min}^{-1}$ (top) and $4{ }^{\circ} \mathrm{C} \cdot \min ^{-1}$ (bottom) under air atmosphere. The curve signals are blue, the integration under the curve is yellow and the simulation is black (Figure S4). Heat flow of the pomace biomass combustion with heating rates $6^{\circ} \mathrm{C} \cdot \mathrm{min}^{-1}$ (top) and $8{ }^{\circ} \mathrm{C} \cdot \mathrm{min}^{-1}$ (bottom) under air atmosphere. The curve signals are blue, the integration under the curve is yellow and the simulation is black (Figure S5). Ten-step mechanism of pyrolysis is proposed according to the parallel decomposition reactions of cellulose, hemicellulose and lignin (Scheme 1). DSC curves of the pomace biomass with different heating rates (i.e. 2, 4, 6 and $8^{\circ} \mathrm{C} \mathrm{min}^{-1}$ ) under air atmosphere (Figure S6). The \% integrated mass derived from the TGA results of heating rates 2 (top) and 4 (bottom) ${ }^{\circ} \mathrm{C} . \mathrm{min}^{-}$

${ }^{1}$. The curve signals are blue, the integration under the curve is yellow and the simulation is black (Figure S7). The \% integrated mass derived from the TGA results of heating rates 6 ( top) and 8 (bottom) ${ }^{\circ} \mathrm{C} \cdot \mathrm{min}^{-1}$. The curve signals are blue, the integration under the curve is yellow and the simulation is black (Figure S8). The activation energy of the pomace biomass combustion using ASTM-E698 and FWO methods derived from the TGA results (Figure S9). The kinetic parameters calculated with the differential iso-conversional, a) natural logarithm of the reaction rate in $\left(\mathrm{s}^{-1}\right)$ versus the inverse temperature, $\left.\mathrm{b}\right)$ Ea and $\ln \mathrm{k}_{0}$ derived from the TGA results (Figure $\mathrm{S} 10$ ).

\section{References:}

1. (a) Venturini, G.; Pizarro-Alonso, A.; Münster, M., How to maximise the value of residual biomass resources: The case of straw in Denmark. Applied Energy 2019, 250, 369-388, https://doi.org/10.1016/j.apenergy.2019.04.166; (b) Osman, A. I.; O'Connor, E.; McSpadden, G.; AbuDahrieh, J. K.; Farrell, C.; Al-Muhtaseb, A. a. H.; Harrison, J.; Rooney, D. W., Upcycling brewer's spent grain waste into activated carbon and carbon nanotubes for energy and other applications via twostage activation. Journal of Chemical Technology \& Biotechnology 2020, 95 (1), 183-195, https://doi.org/10.1002/jctb.6220; (c) Osman, A. I.; Farrell, C.; Al-Muhtaseb, A. a. H.; Harrison, J.; Rooney, D. W., The production and application of carbon nanomaterials from high alkali silicate herbaceous biomass. Scientific Reports 2020, 10 (1), 2563, https://doi.org/10.1038/s41598-02059481-7; (d) Osman, A. I.; Blewitt, J.; Abu-Dahrieh, J. K.; Farrell, C.; Al-Muhtaseb, A. a. H.; Harrison, J.; Rooney, D. W., Production and characterisation of activated carbon and carbon nanotubes from potato peel waste and their application in heavy metal removal. Environmental Science and Pollution Research 2019, 26 (36), 37228-37241, https://doi.org/10.1007/s11356-019-06594-w.

2. (a) Osman, A. I.; Abu-Dahrieh, J. K.; Rooney, D. W.; Thompson, J.; Halawy, S. A.; Mohamed, M. A., Surface hydrophobicity and acidity effect on alumina catalyst in catalytic methanol dehydration reaction. J Chem Technol Biot 2017, 92 (12), 2952-2962, https://doi.org/10.1002/jctb.5371; (b) Chen, H.; Osman, A. I.; Mangwandi, C.; Rooney, D., Upcycling food waste digestate for energy and heavy metal remediation applications. Resources, Conservation \& Recycling: $X$ 2019, 3, 100015, https://doi.org/10.1016/j.rcrx.2019.100015.

3. (a) Fawzy, S.; Osman, A. I.; Doran, J.; Rooney, D. W., Strategies for mitigation of climate change: a review. Environmental Chemistry Letters 2020, https://doi.org/10.1007/s10311-020-01059w; (b) Osman, A. I.; Abdelkader, A.; Johnston, C. R.; Morgan, K.; Rooney, D. W., Thermal Investigation and Kinetic Modeling of Lignocellulosic Biomass Combustion for Energy Production and Other 
Applications. Industrial \& Engineering Chemistry Research 2017, 56 (42), 12119-12130, https://doi.org/10.1021/acs.iecr.7b03478.

4. Sójka, M.; Król, B., Composition of industrial seedless black currant pomace. European Food Research and Technology 2009, 228 (4), 597-605, https://doi.org/10.1007/s00217-008-0968-x.

5. (a) Nawirska, A.; Kwaśniewska, M., Dietary fibre fractions from fruit and vegetable processing waste. Food Chemistry 2005, 91 (2), 221-225, https://doi.org/10.1016/j.foodchem.2003.10.005; (b) Kapasakalidis, P. G.; Rastall, R. A.; Gordon, M. H., Effect of a Cellulase Treatment on Extraction of Antioxidant Phenols from Black Currant (Ribes nigrum L.) Pomace. Journal of Agricultural and Food Chemistry 2009, 57 (10), 4342-4351, https://doi.org/10.1021/jf8029176.

6. (a) Borycka, B.; \& Z_uchowski, J., Metal sorption capacity of fibre preparation from fruit pomace. Polish Journal of Food and Natural Science 1998, 1, 67-76; (b) Larrauri, J. A., New approaches in the preparation of high dietary fibre powders from fruit by-products. Trends in Food Science \& Technology 1999, 10 (1), 3-8, https://doi.org/10.1016/S0924-2244(99)00016-3.

7. Warmer winters threaten UK blackcurrant farming, https://www.sciencedaily.com/releases/2018/12/181217081821.htm, accessed 27-05-2019 at 12 pm.

8. Blackcurrants: Around the World, https://www.eurofreshdistribution.com/news/blackcurrants-around-world, accessed at 27-05-2019 at 3pm.

9. Cao, W.; Martí-Rosselló, T.; Li, J.; Lue, L., Prediction of potassium compounds released from biomass during combustion. Applied Energy 2019, 250, 1696-1705, https://doi.org/10.1016/j.apenergy.2019.05.106.

10. Micić, D. M.; Ostojić, S. B.; Simonović, M. B.; Krstić, G.; Pezo, L. L.; Simonović, B. R., Kinetics of blackberry and raspberry seed oils oxidation by DSC. Thermochimica Acta 2015, 601, 39-44, https://doi.org/10.1016/j.tca.2014.12.018.

11. (a) Kayran, S.; Doymaz, i., Determination of drying kinetics and physicochemical characterization of apricot pomace in hot-air dryer. Journal of Thermal Analysis and Calorimetry 2017, 130 (2), 1163-1170, https://doi.org/10.1007/s10973-017-6504-0; (b) Kumar, N.; Sarkar, B. C.; Sharma, H. K., Mathematical modelling of thin layer hot air drying of carrot pomace. Journal of Food Science and Technology 2012, 49 (1), 33-41, https://doi.org/10.1007/s13197-011-0266-7; (c) Zhang, Q.-A.; Song, Y.; Wang, X.; Zhao, W.-Q.; Fan, X.-H., Mathematical modeling of debittered apricot (Prunus armeniaca L.) kernels during thin-layer drying. CyTA - Journal of Food 2016, 14 (4), 509-517, https://doi.org/10.1080/19476337.2015.1136843; (d) Celma, A. R.; López-Rodríguez, F.; Blázquez, F. C., Experimental modelling of infrared drying of industrial grape by-products. Food and Bioproducts Processing 2009, 87 (4), 247-253, https://doi.org/10.1016/j.fbp.2008.10.005.

12. Brachi, P.; Miccio, F.; Miccio, M.; Ruoppolo, G., Isoconversional kinetic analysis of olive pomace decomposition under torrefaction operating conditions. Fuel Processing Technology 2015, 130, 147-154, https://doi.org/10.1016/j.fuproc.2014.09.043.

13. (a) ASTM, Standard Test Method for Compositional Analysis by Thermogravimetry, https://doi.org/10.1520/E1131-08. 2008; (b) ASTM, Standard Test Method for Ash in Biomass, https://doi.org/10.1520/E1755-01R20. 2020.

14. Cortes, A. M.; Bridgwater, A. V., Kinetic study of the pyrolysis of miscanthus and its acid hydrolysis residue by thermogravimetric analysis. Fuel Processing Technology 2015, 138, 184-193, https://doi.org/10.1016/j.fuproc.2015.05.013.

15. Vyazovkin, S.; Chrissafis, K.; Di Lorenzo, M. L.; Koga, N.; Pijolat, M.; Roduit, B.; Sbirrazzuoli, N.; Suñol, J. J., ICTAC Kinetics Committee recommendations for collecting experimental thermal analysis data for kinetic computations. Thermochimica Acta 2014, 590, 1-23, https://doi.org/10.1016/j.tca.2014.05.036.

16. (a) Hassan, E.-S. R. E.; Mutelet, F.; Moise, J.-C.; Brosse, N., Pretreatment of miscanthus using 1,3-dimethyl-imidazolium methyl phosphonate (DMIMMPh) ionic liquid for glucose recovery and ethanol production. RSC Advances 2015, 5 (75), 61455-61464, https://doi.org/10.1039/C5RA08946H; (b) Osman, A. I.; Ahmed, A. T.; Johnston, C. R.; Rooney, D. W., Physicochemical characterization of 
miscanthus and its application in heavy metals removal from wastewaters. Environmental Progress \& Sustainable Energy 2018, 37 (3), 1058-1067, https://doi.org/10.1002/ep.12783.

17. Wang, S.; Gu, B.-J.; Ganjyal, G. M., Impacts of the inclusion of various fruit pomace types on the expansion of corn starch extrudates. LWT 2019, 110, 223-230, https://doi.org/10.1016/j.lwt.2019.03.094.

18. (a) Manfredi, M.; Barberis, E.; Rava, A.; Robotti, E.; Gosetti, F.; Marengo, E., Portable diffuse reflectance infrared Fourier transform (DRIFT) technique for the non-invasive identification of canvas ground: IR spectra reference collection. Analytical Methods 2015, 7 (6), 2313-2322, https://doi.org/10.1039/C4AY02006E; (b) Fan, M.; Dai, D.; Huang, B. 3 Fourier Transform Infrared Spectroscopy for Natural Fibres, https://doi.org/ 10.5772/35482.

19. Xia, H.; Peng, J.; Zhang, L., Preparation of high surface area activated carbon from Eupatorium adenophorum using $\mathrm{K} 2 \mathrm{CO} 3$ activation by microwave heating. In Green Processing and Synthesis, 2015; Vol. 4, p 299, https://doi.org/10.1515/gps-2015-0025.

20. Osman, A. I., Mass spectrometry study of lignocellulosic biomass combustion and pyrolysis with NOx removal. Renewable Energy 2020, 146, 484-496, https://doi.org/10.1016/j.renene.2019.06.155.

21. Tsaneva, V. N.; Kwapinski, W.; Teng, X.; Glowacki, B. A., Assessment of the structural evolution of carbons from microwave plasma natural gas reforming and biomass pyrolysis using Raman spectroscopy. Carbon 2014, 80, 617-628, https://doi.org/10.1016/j.carbon.2014.09.005.

22. Bhattacharjya, D.; Park, H.-Y.; Kim, M.-S.; Choi, H.-S.; Inamdar, S. N.; Yu, J.-S., Nitrogen-Doped Carbon Nanoparticles by Flame Synthesis as Anode Material for Rechargeable Lithium-Ion Batteries. Langmuir 2014, 30 (1), 318-324, https://doi.org/10.1021/la403366e.

23. Sadri, R.; Hosseini, M.; Kazi, S. N.; Bagheri, S.; Zubir, N.; Solangi, K. H.; Zaharinie, T.; Badarudin, A., A bio-based, facile approach for the preparation of covalently functionalized carbon nanotubes aqueous suspensions and their potential as heat transfer fluids. Journal of Colloid and Interface Science 2017, 504, 115-123, https://doi.org/10.1016/j.jcis.2017.03.051.

24. Yang, J.; He, Q.; Yang, L., A review on hydrothermal co-liquefaction of biomass. Applied Energy 2019, 250, 926-945, https://doi.org/10.1016/j.apenergy.2019.05.033.

25. Sharma, A.; Pareek, V.; Zhang, D., Biomass pyrolysis-A review of modelling, process parameters and catalytic studies. Renewable and Sustainable Energy Reviews 2015, 50, 1081-1096, https://doi.org/10.1016/j.rser.2015.04.193.

26. Fantozzi, F.; Frassoldati, A.; Bartocci, P.; Cinti, G.; Quagliarini, F.; Bidini, G.; Ranzi, E. M., An experimental and kinetic modeling study of glycerol pyrolysis. Applied Energy 2016, 184, 68-76, https://doi.org/10.1016/j.apenergy.2016.10.018.

27. Chen, D.; Zhou, J.; Zhang, Q., Effects of heating rate on slow pyrolysis behavior, kinetic parameters and products properties of moso bamboo. Bioresource Technology 2014, 169, 313-319, https://doi.org/10.1016/j.biortech.2014.07.009.

28. Wang, X.-C.; Fang, J.-H.; Chen, B.-S.; Wang, J.; Wu, J.; Xia, D., Thermal decomposition characteristics and kinetics of methyl linoleate under nitrogen and oxygen atmospheres. Petroleum Science 2015, 12 (3), 518-524, https://doi.org/10.1007/s12182-015-0034-9.

29. Unapumnuk, K.; Keener, T. C.; Lu, M.; Khang, S.-J., Pyrolysis Behavior of Tire-Derived Fuels at Different Temperatures and Heating Rates. Journal of the Air \& Waste Management Association 2006, 56 (5), 618-627, https://doi.org/10.1080/10473289.2006.10464481.

30. Kumar, A.; Wang, L.; Dzenis, Y. A.; Jones, D. D.; Hanna, M. A., Thermogravimetric characterization of corn stover as gasification and pyrolysis feedstock. Biomass and Bioenergy 2008, 32 (5), 460-467, https://doi.org/10.1016/j.biombioe.2007.11.004.

31. Bennini M.A., K. A., Bakhattar I., Asbik M., Boushaki T., Sarh B., Elorf A., Cagnon B., Bonnamy S. , Characterization and combustion of olive pomace in a fixed bed boiler: effects of particle sizes. International Journal of Heat and Technology 2019, 37 (1), 229-238, https://dx.doi.org/10.18280/ijht.370128. 
32. Pala, M.; Kantarli, I. C.; Buyukisik, H. B.; Yanik, J., Hydrothermal carbonization and torrefaction of grape pomace: A comparative evaluation. Bioresource Technology 2014, 161, 255-262, https://doi.org/10.1016/j.biortech.2014.03.052.

33. Álvarez, A.; Pizarro, C.; García, R.; Bueno, J. L.; Lavín, A. G., Determination of kinetic parameters for biomass combustion. Bioresource Technology 2016, 216, 36-43, https://doi.org/10.1016/j.biortech.2016.05.039.

34. Otero, M.; Lobato, A.; Cuetos, M. J.; Sánchez, M. E.; Gómez, X., Digestion of cattle manure: Thermogravimetric kinetic analysis for the evaluation of organic matter conversion. Bioresource Technology 2011, 102 (3), 3404-3410, https://doi.org/10.1016/j.biortech.2010.10.016.

35. Mouritz, A. P.; Mathys, Z.; Gibson, A. G., Heat release of polymer composites in fire. Composites Part A: Applied Science and Manufacturing 2006, 37 (7), 1040-1054, https://doi.org/10.1016/j.compositesa.2005.01.030.

36. (a) Hattingh, B. B.; Everson, R. C.; Neomagus, H. W. J. P.; Bunt, J. R.; van Niekerk, D.; Ashton, B. P., Modeling the Nonisothermal Devolatilization Kinetics of Typical South African Coals. Energy \& Fuels 2014, 28 (2), 920-933, https://doi.org/10.1021/ef402124f; (b) Trninić, M.; Wang, L.; Várhegyi, G.; Grønli, M.; Skreiberg, Ø., Kinetics of Corncob Pyrolysis. Energy \& Fuels 2012, 26 (4), 2005-2013, https://doi.org/10.1021/ef3002668; (c) Jia, C.; Chen, J.; Liang, J.; Song, S.; Liu, K.; Jiang, A.; Wang, Q., Pyrolysis characteristics and kinetic analysis of rice husk. Journal of Thermal Analysis and Calorimetry 2019, https://doi.org/10.1007/s10973-019-08366-7.

37. (a) Osman, A. I.; Farrell, C.; Al-Muhtaseb, A. H.; Al-Fatesh, A. S.; Harrison, J.; Rooney, D. W., Pyrolysis kinetic modelling of abundant plastic waste (PET) and in-situ emission monitoring. Environmental Sciences Europe 2020, 32 (1), 112, https://doi.org/10.1186/s12302-020-00390-x; (b) Akor, C. I.; Osman, A. I.; Farrell, C.; McCallum, C. S.; John Doran, W.; Morgan, K.; Harrison, J.; Walsh, P. J.; Sheldrake, G. N., Thermokinetic Study of Residual Solid Digestate from Anaerobic Digestion. Chemical Engineering Journal 2020, 127039, https://doi.org/10.1016/j.cej.2020.127039.

38. Rony, A. H.; Kong, L.; Lu, W.; Dejam, M.; Adidharma, H.; Gasem, K. A. M.; Zheng, Y.; Norton, U.; Fan, M., Kinetics, thermodynamics, and physical characterization of corn stover (Zea mays) for solar biomass pyrolysis potential analysis. Bioresource Technology 2019, 284, 466-473, https://doi.org/10.1016/j.biortech.2019.03.049.

39. Cai, J.; Xu, D.; Dong, Z.; Yu, X.; Yang, Y.; Banks, S. W.; Bridgwater, A. V., Processing thermogravimetric analysis data for isoconversional kinetic analysis of lignocellulosic biomass pyrolysis: Case study of corn stalk. Renewable and Sustainable Energy Reviews 2018, 82, 2705-2715, https://doi.org/10.1016/j.rser.2017.09.113.

40. Mong G.R., N. J.-H., Chong W.W.F., Ani F.N., Lam S.S., Chong C.T., Kinetic Study of Horse Manure through Thermogravimetric Analysis. Chemical Engineering Transactions 2019, 72, 241-246, https://doi.org/ 10.3303/CET1972041.

41. Farrell, C. C.; Osman, A. I.; Doherty, R.; Saad, M.; Zhang, X.; Murphy, A.; Harrison, J.; Vennard, A. S. M.; Kumaravel, V.; Al-Muhtaseb, A. H.; Rooney, D. W., Technical challenges and opportunities in realising a circular economy for waste photovoltaic modules. Renewable and Sustainable Energy Reviews 2020, 128, 109911, https://doi.org/10.1016/j.rser.2020.109911. 


\section{Graphical abstract:}

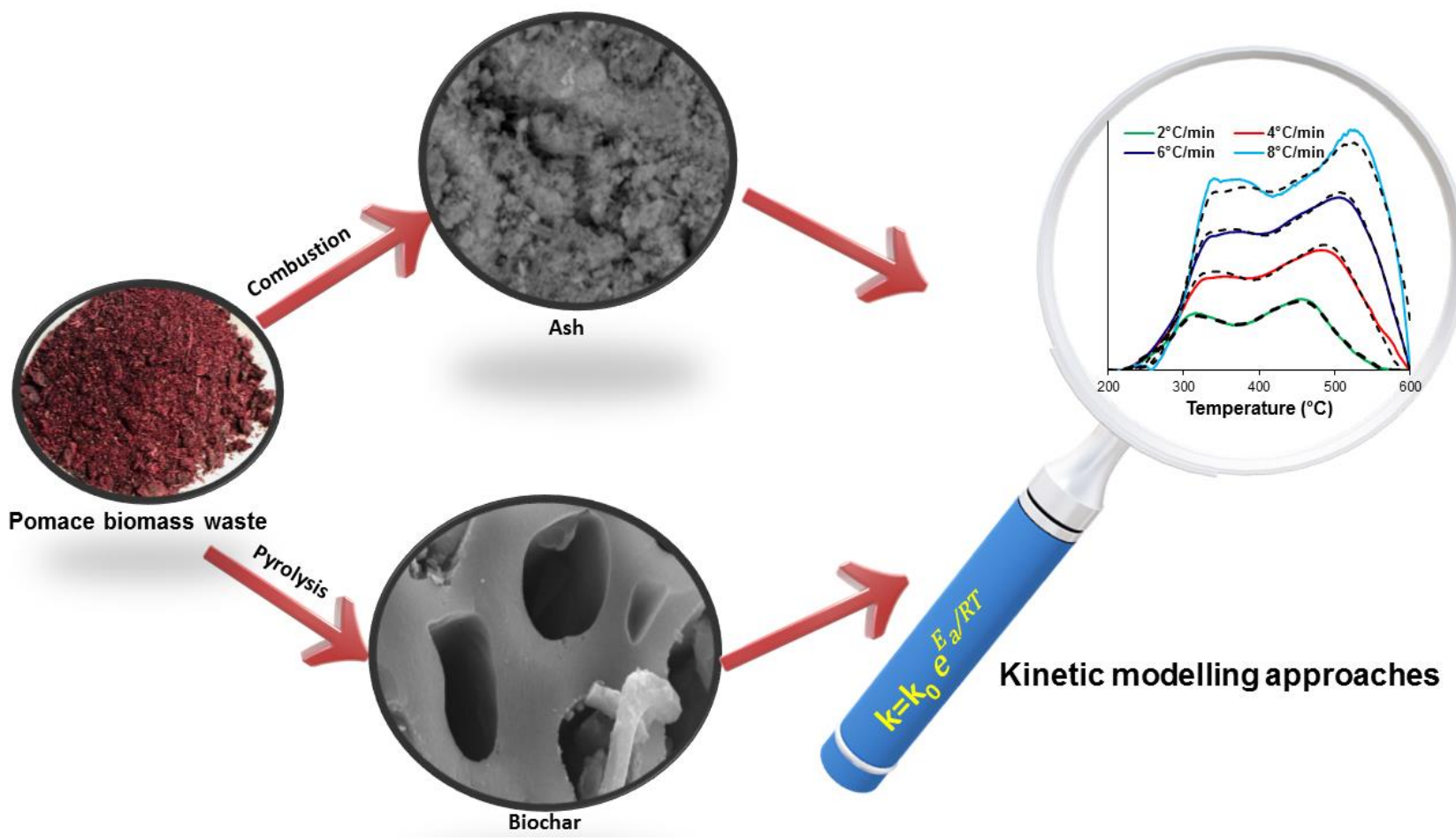

4

5

6 Synopsis sentence:

7 A study of the physicochemical characterisation including the kinetic triplet, thermal 8 predictions via combustion and derived products of waste berry pomace. 